\title{
EMPLEO DEL LENGUAJE FEUDAL COMO LENGUAJE AMOROSO: EL EJEMPLO DEL CANCIONEIRO DE AJUDA
}

\author{
FAUSTINO MARTÍNEZ MARTÍNEZ \\ Departamento de Historia del Derecho y de las Instituciones \\ Instituto de Metodología e Historia de la Ciencia Jurídica \\ Facultad de Derecho. Universidad Complutense de Madrid \\ E-Mail: $\underline{\text { fmartine@der.ucm.es }}$
}

\section{Resumen}

Se estudia en el presente trabajo el modo en que los trovadores galaico-portugueses del siglo XIII procedieron a utilizar en sus composiciones elementos tomados del lenguaje feudal. El feudalismo, llegado por la vía abierta con Europa que constituía el camino de Santiago, aporta no sólo un modo de organizar políticamente la comunidad, sino un lenguaje de la dominación. La poesía recogerá esas palabras (señor, vasallo, hombre, pleito, servicio) empleadas en las cortes para trasladarlas al campo amoroso.

\section{Palabras Clave}

Feudalismo, lírica galaico-portuguesa, trovador, amor cortés, vasallaje, feudo.

\begin{abstract}
The following essay studies how the GalicianPortuguese troubadours of the thirteen century proceeded to employ elements taken from the feudal language in their own compositions. The feudalism, which arrived through the open channel with Europe that the road to Santiago represented, provided not only a political organization of the community, but also a language of the domination. The poetry will collect those words that were usually used at the courts (lord, vassal, man, lawsuit, service) and transfer them to the love field.
\end{abstract}

\section{Keywords}

Feudalism, Galician-Portuguese poetry, troubadour, courtly love, vassalage, fief. 
Si se admite que el feudalismo ${ }^{1}$ puede ser concebido como el motor espiritual y sentimental de la Edad Media en sus primeros siglos ${ }^{2}$, en aquellos tiempos en que la debilidad de un poder central y absorbente impedía hablar de una uniformidad pública y política del territorio y también sobre las personas, es lógico deducir la proyección de todo el caudal lingüístico y conceptual de aquél en las plurales manifestaciones de la cultura. Su pervivencia es asimismo una pervivencia que rebasa los márgenes de lo estrictamente político y desemboca en las aguas de lo cultural. El poder tiende siempre a expandirse, a ocuparlo todo. También el lenguaje. El predominio de esa visión feudal en la mayor parte de las cantigas de amor que componen nuestro cancionero, el Cancioneiro de Ajuda ${ }^{3}$, se puede poner de relieve en una primera consideración de tipo terminológico, pero también conceptual. No sólo las palabras, sino los conceptos son empleados de un modo natural y respetuoso por los trovadores del momento, con estrecha sujeción a su significado natural desde el

${ }^{1}$ El lector puede hallar un catálogo de la mejor bibliografía (por otra parte, inabarcable) sobre el particular en nuestro trabajo: "Un Libro de Feudos gallegos de los siglos XIV y XV (I)", en Dereito. Revista Xurídica da Universidade de Santiago de Compostela, 10, 1 (2001), pp. 98-117.

${ }^{2}$ Expresión de Pichel, A., Ficción poética e vocabulario feudal na lírica trobadoresca galego-portuguesa, La Coruña, 1987, p. 72.

${ }^{3}$ Citaremos por la siguiente edición del Cancioneiro de Ajuda. Edição de Carolina Michaelis de Vasconcelos. Reimpressão da edição de Halle. Imprensa Nacional. Casa da Moeda. Lisboa, 1990. 2 volúmenes (en adelante, Cancionero, referido al tomo I, donde se recogen las cantigas. El tomo II es sumamente recomendable por las noticias históricas y biográficas que proporciona sobre nuestros protagonistas, los trovadores). El Cancionero de Ajuda está datado entorno al año 1275 y fue concebido como tal en una corte, real o señorial, gallega o castellana, próxima al círculo de Alfonso X. Este cancionero constituye la más antigua compilación de esta lírica, luego completada por otros dos: el llamado Colocci-Brancuti y el de la Biblioteca Vaticana. Acerca de la lírica galaico-portuguesa, vid. Filgueira Valverde, J., "Lírica medieval gallega y portuguesa", en Historia General de las Literaturas Hispánicas, publicada bajo la dirección de Guillermo Díaz-Plaja. Volumen 1. Desde los orígenes hasta 1400, Barcelona, 1969, pp. 545-642; Rodríguez Lapa, M., Lições de Literatura portuguesa. Época Medieval. $7^{\mathrm{a}}$ edición, Coimbra, 1970; Fernández del Riego, F., Historia da Literatura galega. $4^{\mathrm{a}}$ edición, Vigo, 1978, pp. 29-57; Saraiva, A. J. y Lopes, O., História da Literatura portuguesa. $11^{\mathrm{a}}$ edición, Oporto, 1979, pp. 35 ss.; Braga, T., Histórica da Literatura portuguesa. Idade Média, Lisboa, 1984; Antología de la poesía gallego-portuguesa. Selección, estudio y notas de Carlos Alvar y Vicente Beltrán, Madrid, 1985, pp. 3 ss.; Tavani, G., "La poesia lirica galego-portoghese", en Köhler, E. (dir.), Grundriss der romanischen Literaturen des Mittelalters. Vol. II, Tome 1, Fascicule 6. Heidelberg, 1980; A poesía lírica galego-portuguesa, Vigo, 1986; y Tra Galizia e Provenza. Saggi sulla poesia medievale galego-portoghese, Roma, 2002; Pena, X. R., Literatura galega medieval. I. A Historia, Barcelona, 1986; Tarrío Varela, A., Literatura galega. Aportacións a unha Historia crítica, Vigo, 1994, pp. 17 ss.; Dronke, P., La lírica en la Edad Media. Barcelona, 1995, pp. 137 ss.; Marcos, A. y Serra, P., Historia de la Literatura portuguesa. Salamanca, 1999, pp. 12 ss.; Machado, A. M., "La poesía trovadoresca gallego-portuguesa", en Gavilanes, J. L. y Apolinário, A. (eds.), Historia de la Literatura portuguesa, Madrid, 2000, pp. 47-83; VV. AA., História da Literatura portuguesa, Lisboa, 2001. Tomo I, pp. 101-161; y Rodríguez Alonso, M., Historia de la Literatura gallega, Madrid, 2002, pp. 16-30. 
punto de vista político. Ese amor cortés que ha nacido adopta el modelo feudal para nutrir sus composiciones: el amor cortés es amor feudal ${ }^{4}$. Veamos, pues, cómo se plasma aquél utilizando elementos de éste 5 .

\footnotetext{
${ }^{4}$ La expresión "amor cortés" es acuñada por G Paris, "Études sur les romans de la Table Ronde. Lancelot du Lac. II: Le conte de la Charrette", en Romania, 12 (1883), pp. 459-534. El término es aceptado por la mayoría de los autores, entendiéndose que forma un concepto medieval perfectamente válido, como expone Ferrante, J. M., "Cortes' Amor in Medieval Texts", en Speculum. A Journal of Medieval Studies, vol. 55, 4 (octubre, 1980), pp. 686-695; y Reiss, E., "Fin' Amors: its History and Meaning in Medieval Literature", en Medieval and Renaissance Studies, 8 (1979), pp. 74-99. Sobre este modelo de amor medieval, vid. Wechssler, E., Das Kulturproblem des Minnesangs, Halle, 1909; Frappier, J., "Vues sur les conceptions courtoises dans les littératures d'oc et d'oil au XII siècle", en Cahiers de Civilisation Médiévale, II (1959), pp. 135-156; Dronke, P., Medieval Latin and the Rise of European Love-Lyric. $2^{\text {a }}$ edición. Oxford, 1968. Tomo I, pp. 1 ss.; Lewis, C. S., La alegoría del amor. Estudio de la tradición medieval, Buenos Aires, 1969, pp. 1-36; Imbs, P., "De la fin'amor", en Cahiers de Civilisation Médiévale, XII (1969), pp. 265-285; Green, O. H., España y la tradición occidental. El espíritu castellano en la literatura desde el Cid hasta Calderón. Biblioteca Románica Hispánica, Madrid, 1969. Tomo I, pp. 94 ss.; Newman, F. X. (ed.), The Meaning of Courtly Love. Papers of the first annual conference of the Center for Medieval and Early Renaissance Studies. State University of New York at Binghamton, Albany, 1972, con bibliografía detallada en pp. 97-102; Marchello-Nizia, Ch., "Amour courtois, société masculine et figures du pouvoir", en Annales. Économies. Sociétés. Civilisations, 36, 6 (noviembre-diciembre, 1981), pp. 969-982; Bornstein, D., voz "Courtly Love", en Dictionary of the Middle Ages, Nueva York, 1983. Tomo III, pp. 667-674; Duby, G., "A propósito del llamado amor cortés", en El amor en la Edad Media y otros ensayos, Madrid, 1988, pp. 66-73; y "El modelo cortés", en Historia de las mujeres en Occidente, bajo la dirección de G. Duby y M. Perrot. Tomo 2. La Edad Media, bajo la dirección de Ch. Klapisch-Zuber, Madrid, 1992, pp. 300-319; y La mujer, el caballero y el cura. El matrimonio en la Francia feudal, Madrid, 1999; Bonnassie, P., Vocabulario básico de Historia medieval. $4^{\mathrm{a}}$ edición, Barcelona, 1994, pp. 21-26; Regnier-Bohler, D., voz "Amor Cortés", en Le Goff, J. y Schmitt, J. C. (eds.), Diccionario razonado del Occidente medieval, Madrid, 2003, pp. 23-29; y Wilson, K. M. y Margolis, N. (eds.), Women in the Middle Ages. An Encyclopedia, Westport / Londres, 2004., con varias voces referidas a esta temática.

${ }^{5}$ La literatura es abundante sobre el entronque feudalismo-amor cortés. Produce esa imagen Guillermo de Aquitania, la incorporan algunos trovadores de la segunda generación y alcanza su máxima fortuna en los de tercera, los del siglo XIII, para convertirse en lugar común. Vid. Wechssler, "Frauendienst und Vassallität", en Zeitschrfit für französische Sprache und Literatur, 24 (1902), pp. 159-190; Pellegrini, S., "Intorno al vassallaggio d'amore nei primi trovatori", en Cultura Neolatina. Revista di Filologia Romanza, 4-5 (1944-1945), pp. 20-36 (= Studi Rolandiani e Trobadorici, Bari, 1964, pp. 178191); Koehler, E., "Observations historiques et sociologiques sur la poésie des troubadours", en Cahiers de Civilisation Médiévale, VII (1964), pp. 27-51; Bezzola, R. R., Les origines et la formation de la littérature courtoise en Occident (500-1200). Déuxieme Partie. La société féodale et la transformation de la littérature de cour, París, 1966. Tomo II, pp. 211 ss.; Cropp. G. M., Le vocabulaire courtois des troubadours de l'époque classique, Ginebra, 1975; De Riquer, M., Los trovadores. Historia literaria y textos, Barcelona, 1975. Tomo I, pp. 77 ss.; Dragonetti, R., La technique poétique des trouvères dans la chanson courtoise. Contribution à l'étude de la rhétorique médiévale. Reimpresión, Ginebra, 1979, pp. 61 ss.; Mattoso, J., "La difusión de la mentalidad vasallática en el lenguaje cotidiano", en Studia Historica. Historia Medieval, IV, 2 (1986), pp. 171-183; y, para el concreto caso gallego-portugués, Pichel Lorenzo, F., ob. cit. supra; y Beltrán, V., A cantiga de amor, Vigo, 1995, pp. 185-189.
} 
Comencemos con el elemento fuerte, poderoso, de la relación. La referencia a la amada se efectúa siempre en un sentido masculino, esto es, típicamente feudal. Se la llama, sin prácticamente excepciones, "señor", así en ese género, aunque se acompañe de adjetivos o posesivos en femenino6. Este "señor" es Dios en algunas ocasiones $^{7}$, al que se le reprocha haber otorgado al vasallo ese otro señor que tanto dolor causa $^{8}$, mas lo usual es que adopte la figura física de una mujer, a pesar del

${ }^{6}$ Así, a modo de ejemplo, en Cancionero, ed. cit. I, 2: "Senhor fremosa, grand'enveja ei”; I, 3: "Senhor fremosa par Deus, gran razon (...) mia senhor (...) mais, mia senhor, direi-vus una ren"; I, 6: "Como vos sodes, mia senhor"; I, 7: "Vos que mi-assi cuitades, mia senhor (...) Mais se mi-o Deus desse ora, mia senhor (...) E quitou-me por sempre, mia senhor"; I, 8: "Se Deus me valha, mia senhor"; I, 9: "E vedes, senhor, por que non"; I, 10: "Quen sen conselho que vos, mia senhor (...) senhor fremosa, porque e por quen"; I, 14: "Por Deus, que vus fez, mia senhor"; I, 15: "De quant'eu sempre desejei / de mia senhor, non end'ei ren"; I, 21: "Punhei eu muit'en me guardar, / quant'eu pude, de mia senhor"; I, 22: "E se vos avedes razon, / senhor, de m'este mal fazer"; I, 24: "Senhor fremosa, fui buscar / conselh', e non-no pud'aver"; I, 26: "A Deus, a quen faz ben querer / senhor, con que pode falar"; I, 27: "Desenjand'eu vos, mia senhor"; I, 36: "Senhor, os que me queren mal"; I, 40: "Ay mia Senhor, se eu non merecesse (...) E mia senhor, se m'eu d'esto temesse"; I, 41: "E essa me ten en poder, / e essa est a mia senhor"; I, 42: "Maravilho-m'eu, mia senhor"; I, 43: "E ¡mal-pecado! Moir'og'eu assi, / de mia senhor longe e desemparado"; I, 45: "Ja, mia senhor, niun prazer"; I, 46: "Senhor fremosa, pois me non queredes"; I, 50: "En tal poder, fremosa mia senhor, / soo de vos qual vus ora direi"; I, 56: "Non ouso dizer nulha ren / a mia senhor"; I, 68: "En gran coita vivo, senhor"; I, 70: "Ir-vus queredes, mia senhor"; I, 98: "Par Deus, senhor, ja eu non ei poder"; I, 108: "Se m'eu de vos partir, ay mia senhor"; I, 111: "De vos, senhor, querria eu saber"; I, 112: "Non me queredes, mia senhor, / fazer ben, enquant'eu viver"; I, 114: "Que grave cousa, senhor, d'endurar"; I, 129: "Nostros Senhor Deus, ¿e por que neguei / a mia senhor quando a eu veer / podia e lhe podera dizer / muitas coitas que por ela levei?"; I, 131: "Senhor, que Deus mui melhor parecer / fez de quantas outras donas eu vi"; I, 147: "Senhor fremosa, no ei og'eu quen"; I, 151: "Senhor fremosa, pois pesar avedes (...) E mia senhor, pois que vus pesa én"; I, 152: "En vus amar, mia senhor, mas ca mi”; I, 153: "Senhor fremosa, pois m'og'eu morrer"; I, 181: "Que sen meu grado m'og'eu partirei / de vos, senhor, u me vus espedir"; I, 189: "Quando vus vi, fremosa mia senhor"; I, 199: "A mia senhor, que me foi amostrar"; I, 200: "Quend'eu podia mia senhor"; I, 201: "Ando coitado por veer / un ome que aquí chegou, / que dizen que viu mia senhor"; I, 204: "juro-vus eu, fremosa mia senhor". Los ejemplos son meramente indicativos. La unanimidad del lenguaje y del sentido es total en este caso.

${ }^{7}$ Cancionero, ed. cit. I, 1: "Deus, meu senhor, se vus prouguer, / vos me tolhede este poder / que eu ei de muito viver; / ca, mentr'eu tal poder ouver' / de viver, nunca perderei esta coita que og'eu ei / d'amor en meu coraçon”; I, 69: “iNostro Senhor! En que vus mereci / por que me fostes tal senhor mostrar"; I, 157: "Nostro Senhor, que mi-a min faz amar / a melhor dona de quantas el fez". Tomo I, 203: "Nostro Senhor que me fez tanto mal, / ainde me podera fazer ben, / se mia senhor, per que este mal ven".

${ }^{8}$ Amor torturado cuya responsabilidad corresponde a Dios, porque ha enamorado al poeta, pero no le permite ni la simple contemplación de la amada señora. Cancionero, ed., cit. I, 82: "De quantos mui coitados son, / a que Deus coita faz aver, / min faz mas coitado viver. / E direi-vus per qual razon: / faz-me queren ben tal senhor, / a mais fremosa nen melhor / do mund', e non mi-a faz ver". Pero no siempre: Cancionero, ed. cit. I, 192: "Que, pois me Deus tan boa senhor deu, / non querria das outras a melhor / eu quere ben por aver seu amor". Hay todavía un pequeño resquicio a la esperanza, en Cancionero, ed. cit. I, 203: "Nostro Senhor que me fez tanto mal, / ainda me podera fazer ben, / se mia senhor, per que este mal ven, / eu visse ced'; e non lhe peço al". 
sustantivo masculino. La feminización del nombre es tardía, pero juega muy bien conforme a los intereses que perseguía el poeta a la hora de destacar lo que se quería subrayar: la idea de un sometimiento absoluto. Señor es indistintamente varón o mujer, pero se aproxima más al primero de ellos. Como todos los nombres que presentan esa terminación, la palabra es indiferente al género femenino durante todo el siglo XIII: se feminiza en ese período de modo analógico y vulgar, para generalizarse en la prosa a partir de la siguiente centuria ${ }^{9}$. Las equivalencias de sus múltiples referencias serían "señora", "mi señora", "señora hermosa". Eventualmente, "señora de mi corazón" 10 , "buena señora"11, o mi "señora y mi bien" 12 , pero con resultados exiguos en comparación con el empleo de las otras fórmulas mencionadas: de las cerca de 725 cantigas de amor conservadas, 572 usan el vocablo referido y solamente las restantes se refieren al objeto del deseo amoroso como "mujer"13 o "dona"14, excepcionalmente "donzela"15, pero son voces éstas que se presentan incapaces de simbolizar la totalidad, el poder absorbente, la contundencia que la primera de ellas tiene dentro de $s^{16}{ }^{16}$. La fuerza de la otra palabra, su expresividad feudalizante la hace convertirse en la fórmula típica de referencia femenina.

"Señor" es en realidad "señora", pero es compendio de los adornos y atributos del hombre feudal. Ello obedece con toda probabilidad al empeño en identificar las virtudes del señor con todas aquellas virtudes características de los caballeros, ligadas indefectiblemente a la condición masculina por cuanto las cuestiones feudales eran, por llamarlas de algún modo, cuestiones a resolver entre varones, nunca entre mujeres, dado el contenido eminentemente militar que aquellas conductas presentaban en la realidad práctica. Lo bélico era masculino y la mujer quedaba apartada de ese campo. El señor es siempre hombre y la forma de referirse a é ha de ser, al mismo tiempo, siempre masculina; sus atributos han de ser varoniles, sus virtudes,

\footnotetext{
${ }^{9}$ Frente a la citada evolución lingüística, se propuso en su día una evolución semántica. Vid. Álvarez Blázquez, J. M., "Sobre la voz señor en los trovadores (Concepto de amor servil)", en Cuadernos de Estudios Gallegos. Tomo V, fasc. 15 (1950), pp. 87-104.

${ }^{10}$ Cancionero, ed. cit. I, 156: "Punhar quer'ora de fazer / a meus olhos mui gran prazer / que lhes non fiz, á gran sazon, / ca lhes quero fazer veer /a senhor do meu coraçon".

${ }^{11}$ Cancionero, ed. cit. I, 192: "Que, pois me Deus tan boa senhor deu".

12 Cancionero, ed. cit. I, 443.: "Que sen meu grado me parti / de mia senhor e do meu ben".

${ }^{13}$ Cancionero, ed. cit. I, 253: "Por tal molher que que'-na vir', dirá".

14 Cancionero, ed. cit. I, 88: "Tan fremosa dona com'ela vi"; I, 107: "Pois me tan boa dona fez morrer"; I, 232: "A boa dona, por que eu trobava".

${ }^{15}$ En los epígrafes de ciertas cantigas figura esta voz para referirse a las mujeres solteras de noble estirpe, en Cancionero, ed. cit. I, 312; I, 315; y I, 394.

${ }^{16}$ Vid. Brea, M., "Dona e Senhor nas cantigas de amor", en Estudios Románicos. Homenaje al profesor Luis Rubio. I. Volumen 4. Universidad de Murcia, Murcia, 1987-1989, pp. 149-170.
} 
derivadas de conductas de hombres en armas. Son pocos los casos que se pueden contar en que se haga una concesión a la feminidad, prácticamente muy restringidos, por no decir nulos en la compilación de Ajuda. La evolución de los propios vocablos en el naciente romance, tanto galaico-portugués como castellano, permite observar el predominio de la fórmula "senior" frente a la fórmula "dominus" 17 , si bien el significado de fondo en ambos casos acabará coincidiendo. Ambos vocablos terminan refiriéndose a una serie de realidades comunes, acaso incidiendo la segunda de estas voces en un contenido de mayor calado económico y el primero político. Señor como rector frente a señor como propietario, parecen ser los términos de una contraposición que no impide el empleo indiscriminado de ambas palabras. Pero fue la voz "senior" la que acabó por triunfar en el campo de las relaciones feudales, vasalláticas o beneficiales, en el sentido de que fue eltérmino empleado para designar al elemento fuerte o preponderante de dichas relaciones: el que recibía la fidelidad, el que entregaba las recompensas, aquél que no era titular de dominio, sino titular de señorío, lo que cualitativamente implicaba un rango mayor, una mayor consideración social, y, por ende, una mayor fuerza e influencia. Puesto que fue precisamente en la Francia carolingia donde se comenzó a emplear y acabó imponiéndose la idea de señor como una de las partes (la parte clave) de la relación feudo-vasallática, su recepción en la documentación de Castilla y León es relativamente temprana y plenamente exitosa, si bien con matices. Galicia conserva la voz "patronus", en León, erudito y cortesano, típicamente latino, prevalece "dominus", mientras que es la innovadora Castilla la que adapta con naturalidad la voz "senior" que iba a triunfar en los siglos centrales del Medievo ${ }^{18}$. Así, Partida 4,

${ }^{17}$ Estimamos que la expresión camina, sobre todo, sobre una base económica que remontaría sus orígenes al Derecho romano. "Dominus" sería el principal de la casa, de la domus, el que ejerce un poder paternal que paulatinamente se va extendiendo sobre otros elementos personales no vinculados necesariamente por lazos de parentesco, teniendo como elemento decisivo de ese poder la propiedad de la tierra. Ese elemento es preponderante. La expresión "dominus" se va a referir, en la vasta documentación alto y centro medieval, a Dios, a los seres celestiales, a las dignidades eclesiásticas, al rey y a los infantes, a los condes, magnates y personajes diversos, a los señores de siervos y a los propietarios de bienes, a los señores de vasallos, al de caballeros villanos y al de quienes habían contraído relaciones de protección y de dependencia, como las behetrías o el caso de los júniores. Vid. Grassotti, H., "Dominus y Dominum en la terminología jurídica de Asturias, León y Castilla (Siglos IXXIII)", en AHDE, 50 (1980), pp. 653-682. Para la caracterización de ese poder doméstico que después deviene territorial, vid. Brunner, O., Terra e Potere. Strutture pre-statuali e pre-moderne nella storia costituzionale dell'Austria medievale, Milán, 1983.

18 Vid. Grassotti, H. ; Las instituciones feudo-vasalláticas en León y Castilla, Spoleto, 1969. Tomo I, pp. 268-270; y "Senior y Seniorium en la terminología jurídica de Castilla y León (Siglos XXIII)", en Cuadernos de Historia de España, 65-66 (1981), pp. 31-58. En la acepción que ahora nos interesa, es recogida en la mayor parte de los diccionarios y repertorios lingüísticos medievales, tanto latinos como romances. Vid. Du Cange, D., Glossarium Mediae et Infimae Latinitatis, Niort, 1886. 
25, 1, texto coetáneo al Cancionero de Ajuda y compendio del Derecho que se empleará en toda la Corona de Castilla para regular estas cuestiones, nos dirá que señor es aquel que "a mandamiento e poderío sobre todos aquellos que biuen en su tierra”. Como señor, dominante, adornado con todas las virtudes, no es precisa ninguna adjetivación posterior. La simple voz es sinónimo de todo lo bueno, lo perfecto, lo bello y lo hermoso. No es precisa concreción ulterior. Eso explica que, ni en el aspecto físico, ni en el espiritual o psicológico, se acumulen elementos descriptivos de la mujer, porque el solo sustantivo se basta y se sobra para designar la realidad a la que se quiere aludir. Una especie de abstracción rodea a la señora amada, de la que no se sabe el nombre regularmente, ni su aspecto externo, ni siquiera el ámbito geográfico en el que se mueve. No hay enumeración de antropónimos, ni de rasgos físicos, ni de lugares, ciudades, villas o aldeas donde aquélla pudiese vivir. Un ambiente de cierta evanescencia e irrealidad lo rodea todo, como si la realidad física no tuviese existencia y, lo que es más, importancia, con una mujer que no se describe y un paisaje que también está ausente.

El señor es el ser perfecto, la totalidad del bien a la que se tiene que tender para alcanzar la perfección y con ella la felicidad, si bien este objetivo se va a ver frustrado de modo sucesivo. Es compendio de todo aquello a lo que tiende el vasallo. Ninguna otra palabra puede aproximarse a describirla ${ }^{19}$ o bien se emplean palabras de una significación general que aluden a su buen aspecto, buen semblante o bello rostro $^{20}$.

La mujer es la suma de todas las virtudes, es el ser perfecto e irrepetible, la mejor creación que Dios ha efectuado, quien aparece así como responsable último

Tomo VII, pp. 421-423; Rodón Binué, E., El lenguaje técnico del feudalismo en el siglo XI en Cataluña (Contribución al estudio del latín medieval), Barcelona, 1957, pp. 231-234; Santa Rosa de Viterbo, J., Elucidário das palavras, termos e frases que em Portugal antigamente se usaram e que hoje regularmente se ignoram. Edición de Mário Fiúza, Oporto / Lisboa, 1966. Tomo II, p. 555; Niermeyer, J. F., Mediae Latinitatis Lexicon Minus. Edición fotomecánica, Leiden, 1984, pp. 956-959; Alonso, M., Diccionario medieval español. De las glosas emilianenses y silentes ( $s$. X) hasta el siglo XV, Salamanca, 1986. Tomo II, p. 1.580; y Léxico hispánico primitivo (Siglos VIII al XII). Edición de Manuel Seco, Madrid, 2004, pp. 584-585.

${ }^{19}$ Cuando existe esa descripción, es esencialmente anímica, referida no a elementos externos, sino a rasgos psicológicos o internos, como se puede ver infra. A modo de ilustración, vid. D’Heur, J. M., Recherches internes sur la lyrique amoureuse des troubadours galiciens-portugais (XII-XIV siècles), París, 1975, pp. 435 ss.

${ }^{20}$ Cancionero, ed. cit. I, 5: "U veja o bon semelhar / da mia senhora, se lhe Deus der', / que a tal fez, end'o poder"; I, 49: "Ca se el vir' o seu bon semelhar / d'esta senhor, por que mi-a mal ven"; I, 55: "Nen a perderá, mia senhor, / quen vir' vosso bon parecer"; y I, 380: "Non poder vosso, nen veer / o vosso mui bon semellar". "Bon semelhar", "bon parecer", "fremoso parecer" y concordantes, se emplean en Cancionero, ed. cit. I, 5, 7, 40, 43, 47, 49, 55, 70, 76, 84, 85, 88, 97, 98, 107, 113, 128, $130,139,141,163,166,246,248,280,287,335,351,369,382$, entre otros muchos ejemplos. 
de la creación y del amor que ha nacido ${ }^{21}$ : la que mejor habla, la más mansa, la más hermosa, la que mejor aspecto presenta, la que mejor regalo es para la vista ${ }^{22}$. El trovador Pero Mafaldo concluye, de forma definitiva, que "a fezo Deus de muito ben senhor / e das melhores donas a melhor" ${ }^{23}$. Joan Soaires Somesso la califica, sin rubor, como la "melhor dona do mundo" 24 , y Pero García Burgalés la define de igual manera ${ }^{25}$. La adoración se ha apoderado de los vates medievales. La fidelidad tiene una primera manifestación en esta exaltación sin límites de la señora amada. La palabra se pone al servicio, valga la redundancia, del propio servicio feudal.

El señor tiene un poder prácticamente ilimitado sobre el vasallo, incluso si se quiere arbitrario, totalizador, absoluto, no sujeto a restricciones, ni a códigos: es "senhor de mi e do meu coraçon", dueño de alma y cuerpo ${ }^{26}$, como se reitera en las

${ }^{21}$ Cancionero, ed. cit. I, 94: "En vos, que fez Deus a melhor / dona de quantas donas vi"; I, 102: "Ca tan fremosa dona nunca fez / Nostro Senhor de quantas donas fez, / nen tan comprida de tod'outro ben!"; I, 118: "E a que Deus fez melhor parecer, / mia senhor est, e senhor das que vi, / de mui bon preço e de mui bon sen, / per boa fe, e de tod'outro ben / de quant'eu nunca d'outra don'oí"; I, 127: "Vi una dona melhor parecer / de quantas outras eno mundo vi"; I, 129: "U a podia eu mui ben veer, / e u a vi mui melhor parecer / de quantas donas vi nen veerei!"; I, 131: "Senhor, que Deus mui melhor parecer / fez de quantas outras donas eu vi"; I, 133: "Sab'oge Deus e sancta Maria, / que a fezeron melhor parecer / de quantas donas vi e mais valer / en todo ben; e ben veeria"; I, 150: "Que vos parecedes melhor / de quantas eu vi, mia senhor"; I, 152: "Por aquel Deus que vus feze nacer / e mui melhor das outras parecer / donas que el en este mundo fez, / e mui mansa e de mui melhor prez"; I, 157: "Nostro Senhor, que mi-a min faz amar / a melhor dona de quantas el fez, / e mais fremosa e de melhor prez, / e a que fez mais fremoso falar"; I, 179: "Por Deus Senhor, que vos tanto ben fez / que vus fezo parecer e falar / melhor, senhor, e melhor semelhar / das outras donas, e de melhor prez"; I, 186: "Por Deus vus quero rogar, mia senhor, / que vus fezo de quantas donas fez / a mais fremosa, nen de melhor prez: / pois todo ben entendedes, senhor"; I, 244: "Deus, que lhe mui bon parecer foi dar (...) Nostro Senhor que lhe deu mui bon prez, / melhor de quantas outras donas vi / viver no mund'; e, de pran, est assi: / Deus que lh'a ela tod'este ben fez".

22 Cancionero, ed. cit. I, 41: "Por ben-prez e por ben-falar, / por bon-sen e per parecer"; I, 88: "Ca non / vi nunca dona tan ben parecer / nen tan flemoso, nen tan ben falar"; I, 101: "Ay, mia senhor e meu lum' e meu ben, / per boa fe, verdade vus direi"; I, 107: "Tanto a vi fremoso parecer / e fremoso falar que sol mester"; I, 140: "Tan mansa vus quis Deus Senhor fazer / e tan fremosa, e tan ben falar"; I, 141: "Cuidando en quanto vus Deus fez de ben / en parecer e en mui ben falar"; I, 161: "Tanto a vi fremoso parecer, / e falar mans', e fremos' e tan ben, / e de tan bon prez, e tan de bon sen / que nunca d'ela mal cuidei prender"; I, 252: "Ca desejos non ei eu de perder / da mansedume e do bon parecer / e da bondade, se eu ben fazer"; I, 254: "Por quan mansa e por quan de bon prez / e por quan aposto vus fez falar"; I, 364: "Per boa fe, fremosa mia senhor, / sei eu ca mais fremoso parecer / vus fez Deus, e mais fremoso falar / de quantas outras donas quis fazer. / E al vus fez que vus ora direi: / fez-vus mais mansa e de mui melhor / doair' e melhor talhada seer".

${ }^{23}$ Cancionero, ed. cit. I, 431.

${ }^{24}$ Cancionero, ed. cit. I, 21.

${ }^{25}$ Cancionero, ed. cit. I, 93: "Por que digo que sodes a melhor / dona do mund'; e verdade direi".

${ }^{26}$ Cancionero, ed. cit. I, 156; I, 169; I, 257; I, 279. 
palabras de Rodrigo Eanes de Vasconcelos ${ }^{27}$, luz con la que se iluminan los ojos del poeta $^{28}$, todo luz y todo bien ${ }^{29}$. Es el señor que domina total y absolutamente, sin recovecos, al vasallo ${ }^{30}$, el cual solamente puede afirmar esa idea: "Ca soo tan en seu poder", dice Osorio Eanes ${ }^{31}$, prueba de ese sometimiento razonado, voluntario, imparable, hasta el punto de que un mundo cruel, injusto, donde no hay mesura, ni grandeza, ni amistad, aquél, el mundo imperfecto es redimido precisamente por la presencia del señor ${ }^{32}$. El poeta lo ha perdido todo, todo lo anterior a su vasallaje amoroso, se entiende, $\mathrm{y}$ ha renunciado al pasado para someterse al poder ilimitado de la señora: ha perdido, dice Pero García Burgalés, "Deus e amigos e esforç' e sen”, Dios, amigos, esfuerzo y el sentido ${ }^{33}$. Nuño Rodríguez de Candarey lo expresa con suma claridad y angustia. El poeta morirá porque así lo quiere su señora, que tiene todo en su poder, la vida y la muerte, y es ésa su voluntad inapelable en el caso de que hubiese merecimiento para dicha sentencia:

\author{
“(...) e ben sei, \\ Senhor, que assi morrerei, \\ Pois assi é vosso prazer, \\ E ben o podedes fazer, \\ Se vus eu morte mereci; \\ Mais, por Deus, guardade-vus i, \\ Ca tod'é en vosso poder. \\ E senhor preguntar-vus ei: \\ Por serviço que vus busquei \\ ¿Se ei por en mort'a prender?"34.
}

\footnotetext{
27 Cancionero, ed. cit. I, 427: "Senhor de mi e do meu coraçon, / dizedes que non avedes poder / per nulha guisa de mi ben fazer", preguntándose por qué no puede hacerle bien de la misma manera que le hace mal: "Mais, mia senhor, dizede-mi una ren: / como mi vos podedes fazer mal, / ¿non mi podedes assi fazer ben?".

${ }^{28}$ Cancionero, ed. cit. I, 421: "Ay mia senhor, lume dos olhos meus".

${ }^{29}$ Cancionero, ed. cit. I, 101; I, 185.

${ }^{30}$ Diferentes fragmentos ponen de manifiesto esta sumisión total, en Cancionero, ed. cit. I, 2, 21 , 22, 40, 41, 54, 55, 68, 156, 213, 250, 285, 296, 297, 305, 306, 346, 361, 386, 427, 440.

${ }^{31}$ Cancionero, ed. cit. I, 320.

${ }^{32}$ Cancionero, ed. cit. I, 305: "Viv'eu en tal mund', e faz m'i viver / una dona que quero mui grande ben; / e muit'á ja que m'en seu poder ten, / ben de-lo temp'u soían amar".

${ }^{33}$ Cancionero, ed. cit. I, 101: "E fez-vus Deus nacer por mal de mi, / senhor fremosa, ca per vos perdi / Deus e amigos e esforç' e sen”. Con otras palabras lo expresa Joan Coelho, en Cancionero, ed. cit. I, 158: "E direi-vus quanto por vos perdi: / perdo o mund', e perdi-me con Deus, / e perdi-me con estes olhos meus; / e meus amigos perden, senhor, mi". Junto a la pérdida del sentido, el otro elemento que tipifica el amor llevado hasta sus máximos extremos es la pérdida del sueño, como Vasco Rodríguez de Calvelo, en Cancionero, ed. cit. I, 297: "Nen seu amor que me forçado ten, / que me tolheu o dormir e o sen".

${ }^{34}$ Cancionero, ed. cit. I, 68.
} 
Roy Queimado dirá que la relación es vitalicia: "Servir-vus ei ja, mentr'eu viver", otro indicio más para resaltar esa capacidad de vinculación a ultranza, prácticamente absoluta, si bien el silencio generalizado de los poetas determina que podamos pensar que dicho vasallaje amatorio siempre presentará esos rasgos desde el momento de la primera visión del señor, momento que implica el inicio de la relación, el comienzo del suplicio, al que solamente la muerte, querida o no querida, parece puede poner fin ${ }^{35}$.

Si el feudo y su relación jurídica es, como señalamos arriba, una relación de protección, fidelidad y dependencia artificial, que se superpone a una relación política natural, trabada con el rey, no deja de sorprender la inclusión en algunos versos de la referencia a la señor como "natural". Aunque Partida 4, 24, 2, califica el vasallaje como un tipo de relación natural, o un tipo de naturaleza, en el sentido de deber que unos hombres tienen con otros "por alguna derecha razon en se amar e en se querer bien"36, no debe olvidarse el componente de artificiosidad que aquél presenta por la necesidad de un expreso pronunciamiento para que nazca, se constituya y se consolide. Esa referencia al señor natural lo hallamos en dos cantigas de Martín Soares. En la primera composición, el lamento del poeta procede de la amargura de amar sin ser correspondido, sentimiento que se dirige a su señora como si fuese precisamente su señor natural, el lógico destinatario de ese amor humano. La elevación de la mujer es aquí incontestable, puesto que desplaza a cualquier otra instancia divina o humana de esa pirámide política, obstaculizada precisamente por el fenómeno feudal:

\footnotetext{
"De tal guisa me ven gran mal

Que nunca de tal guisa vi

Viir a outro, pois nasci.

E direi-vus ora de qual

Guisa, se vus prouguer, me ven:

Ven-me mal, porque quero ben

Mia senhor e mia natural"37.
}

\footnotetext{
35 Cancionero, ed. cit. I, 131.

${ }^{36}$ Partida 4, 25, 1, para el concepto de naturaleza. Se enumeran, a renglón seguido, diez tipos o modos de naturaleza, de las que destacamos las dos primeras: "La primera, e la mejor, es la que han los omes a su señor natural por que tan bien ellos, como aquellos de cuyo linaje descienden, nascieron e fueron raygados, e son en la tierra onde es el Señor. La segunda es la que auiene por vasallaje", en Partida 4, 24, 2. Citamos por la edición anastática del Boletín Oficial del Estado, Madrid, 1974. 3 tomos.

${ }^{37}$ Cancionero, ed. cit. Tomo I, 53.
} 
Es esa relación natural la que justifica en versos posteriores que el poeta se encuentre pleno de derecho para amarla por encima de todas las cosas, empezando por uno mismo ("Que am'eu mais ca min nen al, / e tenho que ei dereit'i / d'amar tal senhor mais ca mi"), aunque en cuestiones amatorias el Derecho no tiene nada que decir ("Mais a min dereito non val"). ¿Qué hacer, pues, si "dereito nen senhor / non me val'i"? Un nuevo recurso feudal es la solución. Buscar el consejo, el consilium, al que también se debe el señor, sin temor a la respuesta, pues cualquiera será buena para el vasallo:
“Quen me conselho der', terrei
Que muit' é bon conselhador.
Ca ela non mi-o quer i dar,
Nen mi-ar poss'eu d'ela quitar.
¿E qual conselh'é qui melhor?
Esforzar-m'en soffrer pavor
O melhor conselh'é que sei,
E en lhe dizer qual tort'ei
E non lh'o negar, pois i for.
E ela faça como vir,
De me matar e me guarir:
E averei de qual quer sabor".

En otra cantiga, el mismo poeta reflexiona sobre lo que se considera elemental en el cosmos político medieval, es decir, que no es errado, ni malo, amar al señor natural (en este caso, la señora) y que así lo debe comprender la destinataria de los versos, pues ella misma es la que es merecedora de aquel calificativo, aunque le pese o moleste ese amor:

“E non tenh'eu que é torto nen mal

D'amar ome sa senhor natural;

Ant'é dereit', e vos vo-l'entendedes" 38 .

Pero pasemos al verdadero señor de todos los seres humanos, habitantes en el reino. El señor natural, es decir, el rey, aparece de modo esporádico en algunas composiciones que tienen como destinatarios a los monarcas del tiempo del cancionero (hablamos del siglo XIII). La propaganda política, teñida de un amor desmedido al monarca, sustituye los recuerdos evocadores de las amadas que han sido

${ }^{38}$ Cancionero, ed. cit. Tomo I, 59. 
y que no han podido ser conquistadas. Hablemos de otros tipo de conquistas. Fernando III, "o mui bon rei, que conquis a fronteira", con ocasión de la toma de Sevilla, es el protagonista de una cantiga de Pero da Ponte. Es el rey que actúa con "razon verdadeira / en todo o mundo temer e mar, este bon rei de prez, valent' e fis", de poder incomparable ("Non foi no mund' emperador nen rei / que tal conquista podesse fazer (...) E mais vus digu: en todas tres las leis / quantas conquistas foron d'outros reis, / apos Sevilla todo non foi ren"), guiado por Dios ("Que Deus manten e guia, / e quer que sempre faça o melhor"), hasta el punto que la conquista de Sevilla es el mejor y mayor presente con que se ha obsequiado a Dios desde su nacimiento:

"E des aquel dia que Deus naceu,

Nunca tan bel presente recebeu

Como del recebeu aquel dia"39.

Su esposa, Beatriz de Suabia, recibe ahora el llanto del mismo poeta, en una cantiga que evoca el paso del tiempo y la generalidad de la muerte, que se ha llevado a la querida y virtuosa reina, anticipando la sensibilidad del otoño medieval de las centurias siguientes:

"En forte ponto et en forte ora

Fez Deus o mundo, pois non leixou i

Nenhun conorto e levou d'aquí

A boa rainha, que end'é fóra:

Dona Beatriz. Direi-vus eu qual:

Non fez Deus outra melhor, nen tal;

Nen de bondade para non lh'acharia

Ome no mundo, par sancta Maria"40.

Lo mismo sucederá con el fallecimiento de Fernando, "que tan ben no mundo fez", suavizado por el hecho de que Dios ha dejado al frente del reino a un dignísimo continuador de la política del padre. El infante Alfonso, futuro Alfonso X, gran señor (natural) que viene a reemplazar a su padre, otro gran señor:

"Mais u Deus pera si levar

Quis o bon rei, i logu' enton

Se nembrou de nos, poi'-lo bon

\footnotetext{
${ }^{39}$ Cancionero, ed. cit. Tomo I, 460.

${ }^{40}$ Cancionero, ed. cit. Tomo I, 461.
} 
Rei don Affonso nus foi dar

Por senhor; e ben nus cobrou,

Ca se nus bon senhor levou,

Mui bon senhor nus foi leixar

E Deus bon senhor nus levou!

Mais, pois nus tan bon rei leixou.

Non nus devemos a queixar

Mais façamus tal oraçon

Que Deus, que pres mort' e paixon,

O mande muito ben reinar!

Amen! Alleluya!"41.

Incluso un monarca alejado geográficamente del entorno castellano-leonés, mas vinculado al mismo por lazos parentales, como sucede con Jaime I, es el protagonista de la última cantiga de Pero da Ponte ${ }^{42}$. Merece citarse, a título anecdótico, la comparación entre el rey de Castilla y el mar, debida a la pluma de Payo Gómez Chariño, marino él mismo, quien se basa para tal equiparación laudatoria en lo mucho que el mar proporciona, su importancia estratégica, su poder, lo inaprensible de su corazón y de sus secretos, su capacidad para infundir temor a todos, su riqueza o su mansedumbre, atributos perfectamente extrapolables al monarca, nuevamente Fernando el Santo ${ }^{43}$.

Esas composiciones panegíricas no pueden evitar el ocultamiento de un fenómeno que sería usual en el Medievo, a causa del cruce de fidelidades. Hay una natural, innata, debida al supremo rector del reino; hay plurales fidelidades de tipo artificial que se conciertan libremente con otros señores. En ocasiones, se producía el choque de estos deberes, la confluencia conflictiva entre el servicio natural al rey y al señor concreto del que se dependía de modo inmediato. El cancionero se hace eco de esto, en el sentido de contraponer la obediencia general a los designios del

\footnotetext{
${ }^{41}$ Cancionero, ed. cit. Tomo I, 462.

42 Cancionero, ed. cit. Tomo I, 465: "O que Valença conquereu / por sempre mais valenç'aver, / Valença se quer manteer, / e sempr' en Valença entendeu. / E de Valença é senhor, / poir el manten prez e valor / e pres VAlença por valer. / E per valença sempre obrou / por aver Valença, de pran; / e por valença lhi diran / que ben Valença gaanhou. / E o bon rei Valença ten; / que, pois prez e valor manten, / rei de Valença lhi diran. / Ca Deus lhi dei esforç' e sen / por sobre Valença reinar, / e lhi fez valença acabar / con quanta valença conven. / El rei que Valença conquis, / que de valença en ben fiz! / e per valença quer obrar. / Rei d'Aragon, rei do bon sen, / rei de prez, rei de todo ben / est, e rei d'Aragon, de pran".

${ }^{43}$ Cancionero, ed. cit. I, 256: "Estas manhas, segundo é meu sen, / que o mar á, á el rei. E por en / se semelhan, que'-no ben entender".
} 
monarca y el cumplimiento exacto de los deberes para con su señora. Airas Corpancho proclama que él desearía servir al rey en su casa (deseo que aparece muchas veces como el remedio para el mal de amor que aqueja al trovador), pero motivos mayores (motivos de amor, en este caso) le retienen junto a su amada:

"Deu-lo sabe que me quisera ir

De coraçon morar a cas del rei" 44 .

En otros casos, como el de Joan Coelho, el bien que se espera de la señora es tal que a su lado ninguno es mensurable. El poeta renuncia aquí a ser rey, infante o emperador a cambio de que "ela fazer / quisesse ben"45. Pero cuando el rey llama a sus filas, ningún obstáculo puede interponerse en esa voluntad regia, aun cuando cause las mayores penas y afliciones. El llanto es ahora de Pedro Eanes Solaz, quien marcha a la corte, pero con un ánimo cabizbajo que le llevará a arrastrar su pena por dondequiera que vaya:

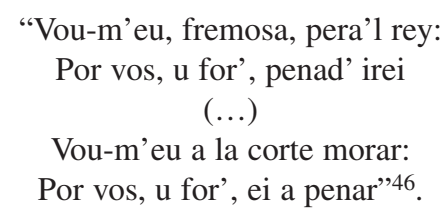

Fernán Paes de Talamancos no duda en calificar de "gran mal" la llamada del monarca, no obstante reiterarle su fidelidad y su voluntad de servicio. Se deja entrever la pérdida del amor del monarca y un lamento más paisajístico que personal, acaso fruto de la afición adquirida en el cumplimiento de los deberes del buen vasallo:

\footnotetext{
"Gran mal me faz agora 'l rei

Que sempre servi e amei,

Porque me parte d'u eu ei

Prazer e sabor de guarir

Se m'eu da Marinha partir,

Non poderei alhur guarir.
}

\footnotetext{
${ }^{44}$ Cancionero, ed. cit. I, 64: "Mais direi-vus por que o leixei: / por amor que mi-o non quis consentir. / E pois amor non me leixa partir / da mia senhor, nen d'aqueste logar, / quen me quiser', venha m'aquí buscar".

${ }^{45}$ Cancionero, ed. cit. I, 171.

${ }^{46}$ Cancionero, ed. cit. I, 284.
} 


\begin{abstract}
Muit'é contra mi, pecador,
El rei, forte e sen amor,

Porque me quita do sabor

E grande prazer de guarir.

Se m'eu da Marinha partir,

Non poderei alhur guarir"47.
\end{abstract}

Pero dejemos al señor, feudal o natural, para observar a la otra parte de la relación, la parte débil, la parte sometida, cuya voluntad libre se ha sometido a un proceso de autodestrucción. El poeta enamorado se ha transformado en "vasallo", en servidor, voz asimismo de procedencia franca generalizada en la Península Ibérica desde el siglo X en adelante, con amplia pluralidad de acepciones, más allá del significado originario: vasallo será no sólo el que ha concertado el pacto vasallático, el fiel y leal servidor del señor, sino también una amplia gama de sujetos a los que se extiende el mismo calificativo ${ }^{48}$. Interesa retener, de todos modos, el significado primigenio: vasallo es el fiel, el que se haya ligado con el señor a través del pacto de fidelidad, sin indicaciones ulteriores acerca de la condición social concreta que le corresponde, ya noble, ya caballero, ya villano. Partida 4, 25, 1 define a los vasallos como aquellos que reciben honra o "bien fecho" de los señores, en forma de caballería, de tierra o de dinero por servicio señalado, insistiendo en la idea de investidura, de recepción de bienes y servicios de la parte del señor y obviando lo que es el compromiso previo que aquél concierta, clave en la configuración institucional de la relación ${ }^{49}$. Es esta acepción la que ahora interesa, la que ahora se destaca. Es indiferente el grupo social puesto que la relación vasallático-amorosa no conoce de diferenciaciones estamentales ${ }^{50}$. El vasallo nace a una nueva vida en el

47 Cancionero, ed. cit. I, 362.

48 Vid. Grassotti, H., Las instituciones feudo-vasalláticas en León y Castilla, ed. cit. Tomo I, pp. 33 ss. Vasallos serán los que reciban prestimonios no gratuitos, laicos o eclesiásticos, los súbditos o naturales del rey, algunos concejos de realengo o sus habitantes, los moradores de ciudades y villas de señorío laico y eclesiástico, así como las gentes de condición inferior en situación de dependencia dominical. Para la voz "vassallus" o "vassus", vid. Du Cange, D., Glossarium Mediae et Infimae Latinitatis. Niort, 1887. Tomo VIII, pp. 249-252; Rodón Minué, E., El lenguaje técnico del feudalismo, ed. cit., p. 254; Santa Rosa de Viterbo, J., Elucidário, ed. cit. Tomo II, pp. 625-626; Niermeyer, J. F., Mediae Latinitatis Lexicon Minus, ed. cit., pp. 1.061-1.064; Alonso, M., Diccionario medieval español, ed. cit. Tomo II, p. 1.616; y Léxico hispánico primitivo, ed. cit., pp. 642-643.

49 Partida 4, 25, 1: "Señor es llamado propriamente aquel que a mandamiento e poderio sobre todos aquellos que biuen en su tierra (...) E vassallos son aquellos que reciben honrra o bien fecho de los señores assi como caualleria, o tierra, o dineros por seruicio señalado que les ayan de fazer".

50 Solamente en un pasaje se habla de "cavaleiro" para indicar esa diferenciación, en Cancionero, ed. cit. I, 317. Fuera de ese ejemplo no hay alusiones a la vida anterior del enamorado, ya vasallo con plenos efectos y con cancelación de la vida anterior. 
instante mismo en que declara su amor, acto en el cual se produce la entrega personal al señor siguiendo los rituales típicos del feudalismo, aunque el cancionero guarda silencio respecto a estos extremos. Basta la simple contemplación de la mujer amada, de ese ser que devendrá señora para que en el alma del poeta nazca el deseo inextinguible de convertirse en su perpetuo servidor: las formalidades y las solemnidades del feudalismo (besamanos, homenaje, juramento) son reemplazadas por una declaración unilateral de voluntad que acaba vinculando a los dos sujetos implicados. Los poetas pasan por alto este componente formal (si bien en algunos casos se referirán, como se verá, al pleito o al pleito-homenaje) porque lo que realmente les interesa es la conclusión de esa nueva relación, sus puntuales consecuencias derivadas, las nuevas realidades que se han alumbrado con la entrega a favor de la señora. Se ha producido ya el cambio. Muchos pasajes reflejan este momento de transformación jurídica, en que la voluntad del primero queda anulada y se inicia una nueva relación de sujeción, de dependencia, de protección. Vasco Praga de Sandín nos introduce en esa nueva dinámica en la que el trovador queda. Inicia su cantiga con un "Como vos sodes, mia señor, / mui quite de me ben fazer", refiriéndose así a los beneficios que aguarda recibir del señor, basándose en la buena fe recíproca que entre ellos se establece, que le lleva a "aver vosso ben", procurar el bien de la señora, para concluir definiendo el vasallaje irremisible que se acaba de construir, que anula la libertad del nuevo servidor, pero también la de la señora que se haya atada por ese "preito":

"Mais vos en preito sodes én,

Ca me vus non quit'eu por én

De vosso vassalo seer" ${ }^{\prime 1}$.

Joan Soaires Somesso no habla de vasallo, sino que se refiere a otro término más expresivo e igual de contundente, que en el siglo XIII formaba parte del vocabulario feudal en el mismo sentido que el anteriormente referido: se trata de la voz "hombre" 52 . El poeta ha devenido hombre con mayúsculas, servidor y servidor ade-

${ }^{51}$ Cancionero, ed. cit. I, 6. Otras, escasas, referencias a vasallo, en Cancionero, ed. cit. I, 342: "Ora faz a min mia senhor, / como senhor pode fazer / a vassalo, que defender / non se pode, nen á u lh'ir"; I, 402: "E a min faz og' el mayor pesar / de quantos outros seus vassalos son”; I, 428: "D'eu por vassalo, e vos por senhor".

52 Cfr. Grassotti, H., Las instituciones feudo-vasalláticas en León y Castilla, ed. cit. Tomo I, p. 66: "A diferencia de lo que ocurría en la Europa feudal donde el término homo se jerarquizó despaciosamente y llegó a significar vasallo - hacia el siglo XIII homines se llamó por antonomasia a quienes había prestado el homenaje vasallático- en León y Castilla el vocablo no sufrió el mismo proceso ascensional". En Cataluña, por ejemplo, era sinónimo de vasallo, pero si este término impli- 
más militar. Pero en el caso concreto del poema que nos ocupa la relación se ha roto, se ha partido y el vasallo debe marchar (sin indicación de los motivos, aunque de nuevo puede ser el sufrimiento amoroso). Por esa razón, el trovador tiene que marchar de su tierra y estar dispuesto a combatir a su antiguo señor, porque aunque le pese, ha de partir, ha de abandonar a aquel señor que tan mal se ha portado con él, no obstante su deseo de morir por la misma señora:

"E ja que m'end'a partir ei,

Esto pod'ela veer ben,

Que muita guerra the farei,

Porque me faz partir d'aquen,

Ond'eu son mui natural;

E sei lh'eu un seu ome atal

Qual averá morrer por én" ${ }^{\prime 3}$.

Lo mismo hace un poeta anónimo unos fragmentos más adelante, reiterando el significado de hombre como servidor y recordando la exigencia de que el buen servicio del vasallo se debe ver acompañado por el correspondiente premio del señor para con él:

"Mais ambos i faredes o melhor, Ca pois omen ben serv'a bon senhor, Bon galardon debe d'ess'a levar"54.

El hombre, como sinónimo de vasallo, aparece esporádicamente en otra serie de versos. Martín Soares, uno de los más tristes y pesimistas de entre todos los trovadores, se lamentan de que la señora haya dejado "assi voss'om' en tal cuita

caba necesaria e implícitamente la dependencia para con un señor, la voz "homo" se acompañaba de una construcción: "esse homo alicuius", ser hombre de alguien. Cfr. Rodón Binué, E., El lenguaje técnico del feudalismo, ed. cit., pp. 138-141. Además de las que se citan adelante, referencias a hombre como sinónimo de servidor en Cancionero, ed. cit. I, 42: "Voss'om' en tal cuita viver"; I, 45: "Com'om' a que, senhor, non val”; I, 49: "Nen outr'ome que tal senhor amar"; I, 52: "En guarirdes voss' ome que matades"; I, 58: "E se me quiserdes guardar / de morte, guardaredes i / voss' ome, se guardardes mi"; I, 187: "Nunc'assi ome de senhor / esteve com og'eu estou"; I, 303: "Mais ambos i paredes o melhor, / ca pois omen ben serv'a bon senhor, / bon galardon debe d'ess'a levar"; I, 363: "Que m'eu por en non possa creer / sempre voss'omen'e al non"; I, 396: "Venho-vus rogar / por un meu omen que non quer servir"; I, 398: "Pois boas donas son desamparadas / e nulho omen no'-nas quer defender"; I, 445: "E vosso fui, senhor, des que vus vi; / e fora mias, se non morress' assi".

${ }^{53}$ Cancionero, ed. cit. I, 15.

${ }^{54}$ Cancionero, ed. cit. I, 303. 
viver" 55 . Otro trovador desconocido afirma lleno de orgullo que servirá hasta la muerte a su señora, que "sempr'andarei por voss'om, e servir-vos-ei", reiterando su fidelidad servicial:

"Ca mentr' eu no mundo viver,
Non quer' outra senhor filhar
Se non vos, se vos non pesar"

Hombre o vasallo se omiten con el posesivo vuestro. Así, el poeta anónimo reconoce que ama y sirve todo cuanto puede y se complace de ser vasallo de su señora, a pesar de que ésta no le valora lo suficiente:

"Am' e sirvo quanto posso,

E praz-me de seer vosso;

E sol que a mia senhor

Non pesasse meu serviço, Deus non me dess' outro viço!

Mais fazend'eu o melhor"

La arbitrariedad de la señora le lleva al lamento que actúa como estribillo:
"Contra mia desaventura
Non val amar, nen servir;
Non val razon, nen mesura;
Nen val calar, nen pedir" 57 .

Idéntica referencia aparece en unos versos de Nuño Rodríguez de Candarey, quién se pregunta cómo ha podido ser tan injusta la señora en su comportamiento para con el poeta, que es su hombre, su vasallo:

"Pero d'al vus preguntarei:

¿Cómo podedes desamar

Quen s'assi por voss'ome ten?"58.

\footnotetext{
55 Cancionero, ed. cit. I, 42.

${ }^{56}$ Cancionero, ed. cit. I, 276.

${ }^{57}$ Cancionero, ed. cit. I, 307.

${ }^{58}$ Cancionero, ed. cit. I, 400.
} 
Eventualmente, surgen otras calificaciones como "servidor" 59 o como "trovador" ${ }^{60}$, en cuanto que servir y trovar son elementos indisociables de la realidad institucional que se ha constituido, son las modalidades exteriores más señaladas por medio de las cuales se hace presente el servicio al que se ha comprometido el vasallo.

Fernán González de Seara se lamenta asimismo de que su muerte, debida al sufrimiento amoroso causado desde el instante en que contempló a la señora, impedirá seguir realizando el servicio amoroso al que se debía:

"E vosso fui, senhor, des que vus vi;

E fora mais, se non moress'assi!"61.

El ya referido Somesso alude al dolido y sufriente amante ahora como vasallo, que ve en su horizonte único la cercanía de la muerte por los amargos tragos que la señora le hace pasar:

$$
\text { “(...) E por én, }
$$

Un vassalo soo que á,

De pran, de morte perde-1-á

Por esta cuita en que me ten" ${ }^{2}$.

También ese vasallo sufriente, cuyo dolor no admite comparación con el de ningún otro vasallo. Es aquél el vasallo que más amargura recibe, sin defensa alguna, como dice Nuño Fernández Torneol, pidiéndole a Dios la muerte para evitar las duras cuitas de amor en las que está encerrado:

"E a min faz og'el mayor pesar

De quantos outros seus vassalos son;

E a este mal non lh'ei defensor:

$\mathrm{U}$ me ten en poder, quer me matar.

Nostro Senhor, non me leixes viver,

Se estas coitas non ei a perder" ${ }^{\prime 63}$.

\footnotetext{
${ }^{59}$ Cancionero, ed. cit. I, 253: "Ela, pero sei que lhe prazerá / de mia morte; ca non quis, nen querrá, / nen quer que eu seja seu servidor".

${ }^{60}$ Cancionero, ed. cit. I, 279: "Pero eu vejo aquí trobadores, / senhor e lume d'estes olhos meus, / que troban d'amor por sas senhores / non vej'eu aquí trobador, par Deus, / que m'og'entenda o por que digo: / al é Alfanx' e al Seserigo".

${ }^{61}$ Cancionero, ed. cit. I, 445.

${ }^{62}$ Cancionero, ed. cit. I, 18.

${ }^{63}$ Cancionero, ed. cit. Tomo I, 402.
} 
Nuevamente las cuitas amorosas sirven de preludio para emplear los términos feudales apropiados. Rodrigo Eanes de Vasconcelos lo hace en una cantiga de amor en que la amada aparece primero como amigo y luego como señora. El sinalagma que implica el contrato feudal se manifiesta de forma extrema hasta el punto que, como dice el estribillo, no se llega a saber quién de los dos, si el vasallo o el señor, es el que más sufre por la relación, pues tal es la igualdad de deberes dolorosos que se ha forjado entre las partes:

"Aquestas coitas que de sofrer ei,

Meu amigo, muitas e graves son;

E vos mui graves —á i gran sazon-

Coitas sofredes; e por én non sei,

D'eu por vassalo, e vos por senhor,

De nos qual sofre mais coita d'amor!"64.

La influencia feudal franca se puede ver no sólo en la terminología, sino incluso en el empleo del mismo romance provenzal para sancionar la condición de "hombre-ligio" 65 que adquiere el poeta frente a su señora. Lo expresa así Fernán García Esgaravunha, en el estribillo de su cantiga:

"Dizer-vus quer'eu uha ren,

Senhor que sempre ben quige:

Or sachiez veroyamen

Que je soy votr'ome-lige"66.

${ }^{64}$ Cancionero, ed. cit. Tomo I, 428.

65 "Hombre ligio" es aquel vasallo, que ha concertado pacto con varios señores, pero, dentro de esa maraña, especialmente con uno de ellos, pacto éste que adquiere preponderancia. Esta fidelidad especial le lleva a colocar esa relación por encima de cualquiera de las otras en caso de que se produzcan conflictos entre los diferentes señores. Vid. García-Gallo, A., Manual de Historia del Derecho español. I. El origen y la evolución del Derecho. $8^{\text {a }}$ edición. $10^{\mathrm{a}}$ reimpresión, Madrid, 1984, pp. 599-600: "Cuando esto ocurre, y ante la posibilidad de que los distintos señores tengan intereses encontrados y todos ellos reclamen al vasallo su ayuda, se llega a distinguir dos clases de homenaje. Uno de ellos es integrum o solidum, pleno, y cualquier otro es planum, llano, simple. Por el primero el vasallo se convierte, según se dice en Cataluña, en homo solidus et alecris (del latín alacer, alicer, alegre, pronto, dispuesto) u homen soliu et alegre, hombre completo y dispuesto - fuera de España se le llama ligio (del alemán ledig, libre de otro lazo)—, y en realidad lo es, pues sirve al señor contra todos los hombres, mientras que el vasallo simple exceptúa de su servicio el actuar contra su senior solidus".

${ }^{66}$ Cancionero, ed. cit. I, 126. 
En otras ocasiones, se emplea alguna construcción que de modo indirecto, a través de perífrasis, alude a esta relación trabada entre el señor y su hombre, recalcando su carácter único, original, exclusivo:

"Nunc'assi ome de senhor

Esteve com og'eu estou"67.

Se citan algunas instituciones características, como el conocido pleito-homenaje, singular de la región galaico-portuguesa, pacto que se concertaba en el sentido de una promesa nobiliaria de cumplimiento de compromisos que se veían reforzados por la entrada en homenaje de los nobles que realizaban tales pactos. Promesa y fidelidad se daban la mano en esta peculiar forma de reforzamiento de alianzas señoriales con la grave consecuencia de incurrir en traición en el caso de incumplimiento:

“O meu amig', amiga, que me gran ben fazia

Fez-me preit' e menage que ante me veria" 68 .

Porque, no obstante, la dureza, el sufrimiento, la extrema sujeción, no obstante todo lo negativo que la relación frustrada ha comportado, ninguno de nuestros trovadores es capaz de separarse de su respectivo señor. Ahora es Pero Mafaldo el que habla para decirnos que, a pesar de los consejos recibidos de sus amigos y a pesar de la falta de reciprocidad, el vínculo debe mantenerse, el servicio debe continuar, y los nombres deben seguir utilizándose en su sentido jurídico primitivo, porque sigue existiendo una confianza ciega en que el señor siempre obrará del mejor modo posible para con su vasallo:

"Ay mia senhor! Veen-me conselhar

Meus amigos, como vus eu disser:

Que vus non servia, ca non m'é mester,

Ca nunca ren por mi quisestes dar!

Pero, senhor, non m'én quer'eu quitar

De vus servir e vus chamar senhor;

E vos paredes depoi'lo melhor!" 69 .

${ }^{67}$ Cancionero, ed. cit. I, 187.

${ }^{68}$ Cancionero, ed. cit. I, 444. También en Cancionero, ed. cit. I, 290: "E non me val i preito nen menage, / e ides-vus e me desamparades, / desampare vos Deus, a que o eu digo". Sobre el pleitohomenaje, vid. Grassotti, H., Las instituciones feudo-vasalláticas en León y Castilla, ed. cit. Tomo I, pp. 216 ss.

${ }^{69}$ Cancionero, ed. cit. I, 430. 
La construcción y la descripción de la relación vasallática se articula de forma negativa, en forma de lamento por lo que no se puede alcanzar, ni realizar, en la que el vasallo expone lo que la señora no ha hecho y de ella se esperaba, de haberse comportado de forma leal, noble, justa ${ }^{70}$. Roi Queimado expresa abiertamente esa queja ${ }^{71}$, ese incumplimiento claro del sinalagma, por parte de la señora:

"Senhor fremosa, vejo-vus queixar

Porque vus am'e amei, pois vus vi;

E pois vos d'esto queixades de mi, Se en dereito queredes filhar, Aque-m'aquí eno vosso poder;

Pois vos de min non queixades por al,

Se non porque vus quero mui gran ben,

E vejo que vos queixades por en,

Senhor de min, e meu ben e meu mal,

Aque-m'aquí eno vosso poderi

Senhor, se vos teedes por razon

D'eu por aquesto ja morte prender,

Non ei eu quen me de vos defender:

E por en, coita do meu coraçon,

Aque-m'aquí eno vosso poder,

En que foi sempr'e ei ja de seer"72.

No hay, sin embargo, una enumeración taxativa de aquellos componentes que se exigían a ambas las partes de la relación, de ese auxilio y de ese consejo recíprocos, de esa actitud ante la vida que llevase a rodearse de aquellos adjetivos que, de acuerdo con Fulberto de Chartres, calificarían a todo buen vasallo: "sain et sauf, sûr, honnê-

${ }^{70}$ Cancionero, ed. cit. I, 46: “¿Qué farei eu, pois mi-a vos non creedes? / ¿Qué farei ei, cativo pecador? / ¿Qué farei eu, vivendo sempre assi? / ¿Qué farei eu, que mal-dia naci? / ¿Qué farei eu, pois me vos non valedes? / E pois que Deus non quer que me valhades, / nen me queirades mia coita creer, / ¿Qué farei eu? Por Deus, que mi-o digades, / ¿Qué farei eu, se logo non morrer? / ¿Qué farei eu, se mais a viver ei? / ¿Qué farei eu, que conselho non sei? / ¿Qué farei eu, que vos desamparades?".

${ }^{71}$ Es éste uno de los más celebrados trovadores, obsesionado con la muerte que pudiera causar la cuita de amor. Vid Manero Sorolla, M. P., "Aproximaciones a la lírica de Roy Queimado: en torno a las cantigas paródicas", en Anuario de Estudios Medievales, 13 (1983), pp. 279-290; y "Técnicas poéticas en las cantigas de amor de Roy Queimado", en ibidem, 17 (1987), pp. 149169.

${ }^{72}$ Cancionero, ed. cit. I, 138. 
te, utile, facile, possible"73. También Partida 4, 25, 6, se refería a la relación entre vasallo y señor en términos jurídicos que acentuaban la humanidad de la relación: deben, ambas partes, amarse, honrarse, "e guardar, e adelantar su pro, e desviarles su daño en todas maneras que pudiere. E debenlos servir bien e lealmente por el bien hecho que de ellos reciben"74. Solamente cuando se da esa reciprocidad, nace, crece y dura el amor verdadero entre ellos. No es así en la lírica. Hay quien cumple, el vasallo; hay quien incumple, el señor, que no va a dar el paso decisivo hacia la investidura feudal, no va a hacer efectivos sus propios compromisos, a entregar el amor que es el único beneficio o feudo que el vasallo ansía. Acaso por tal razón, esto es, la inexistencia del beneficio, la palabra "feudo" está ausente de nuestro vocabulario literario, además de por la causa apuntada: la inexistencia realmente de una institución de tales perfiles en nuestro Medievo. Por eso, el amor perfecto, pleno, completo, correspondido, recíproco, no llega a asomar, no aparece por ningún lado, porque no llega a existir. Falta la culminación de esa relación. Los incumplimientos de la señora amada sirven para que el vasallo trovador reivindique el exacto cumplimiento de los servicios, de la buena fe y de las obligaciones esenciales de todo buen señor, lo que de ella se busca conforme a los usos, estilos, prácticas y costumbre feudales.

Por ese motivo, afirmamos que se llega a la esencia de la relación por la vía de la negación de la relación, no mediante su afirmación. Se decribe lo que falta, no lo

${ }^{73}$ Carta de Fulberto de Chartres al duque de Aquitania. Año 1020: "Al Muy Glorioso duque de Aquitania Guillermo, Fulbert, obispo. Invitado a escribir sobre el tenor de la fidelidad, he anotado rápidamente lo que sigue, consultado los libros que dictan autoridad. Aquel que jura fidelidad a su señor debe tener siempre presente las seis palabras siguientes: sano y salvo, seguro, honrado, útil, fácil, posible. Sano y salvo a fin que no cause daño corporal alguno al señor. Seguro, a fin que no divulgue sus secretos, ni afecte a las obras fortificadas que le procuran seguridad. Honesto, a fin que no atente contra sus derechos de justicia, ni a otros elementos que comprometan su honor. Útil, a fin que no dañe sus posesiones. Fácil y posible, a fin que el bien que su señor pueda hacer con holgura no lo torne difícil, y lo posible devenga imposible. Es justo que el fiel evite actos perniciosos. Pero con esto no merece aún su radiación. Pues no es suficiente abstenerse de hacer mal, es necesario también hacer bien". El texto original en francés en Boutruche, R., Seigneurie et Féodalité. La premier âge. Des liens d'homme à homme. $2^{\mathrm{a}}$ edición revisada y aumentada, París, 1968, p. 405. Documents, $\mathrm{n}^{\circ}$. 54. La traducción en Valdeón Baruque, J., El feudalismo, Madrid, 1992, p. 164. Esa carta se incorporó a los Libri Feudorum 2, 6, 1, De forma fidelitatis.

${ }^{74}$ Partida 4, 25, 6: "Debdos muy grandes son los que han los vassallos con los Señores. Ca deuen los amar e honrar e guardar e adelantar su pro, e desuiarles su daño en todas maneras que pudieren. E deuenlos seruir bien e lealmente por el bien fecho que dellos resciben. Otrosi dezimos que el señor deue amar e honrrar e guardar sus vassallos e fazerles bien e merced e desuiarles daño e desonrra. E quando estos debdos son bien guardados faze cada uno lo que deue e cresce e dura el amor verdadero entre ellos. Otros debdos y ha de muchas maneras entre los vassallos e los Señores, que son tenudos de guardar los unos a los otros, en tiempo de guerra e de paz e de que diximos en la segunda partida deste libro, en las leyes que fablan en esta razon". 
que existe. Dibujamos la relación precisamente por lo que denuncia el vasallo, por aquello que está ausente y debería estar presente. Este es el dilema que se vislumbra en todo el cancionero: la reivindicación de un exacto cumplimiento que dé al vasallo aquello que le corresponde precisamente por haber sido fiel, sumiso, leal, estrictamente cumplidor de aquellos servicios que debía a su señora. He aquí el drama, porque el amor le ciega tan poderosamente que ni siquiera está dispuesto a exigirle ese cumplimiento, aunque lo desea, aunque tiene todo el derecho del mundo a ello, aunque posee toda la razón para la exigencia.

Los poetas galaico-portugueses no cesan de afirmar su servicio ejemplar, su buena $\mathrm{fe}^{75}$, la confianza que inspira y rige la relación ${ }^{76}$, su lealtad ${ }^{77}$ (con su corolario capital: no tener otro señor al que servir de igual manera ${ }^{78}$ ), su mesura en la conducta como expresión de una comedida actitud palaciega y cortesana ${ }^{79}$, el valor y respeto al pacto concertado ${ }^{80}$, la exigencia de un premio ${ }^{81}$ o galardón ${ }^{82}$ (incluso bajo la forma de merced, de petición al margen del Derecho y de sus exigencias ${ }^{83}$ ), como recom-

${ }^{75}$ Las referencias a la buena fe, tanto del señor como, sobre todo, del vasallo, son numerosísimas, en Cancionero, ed. cit. I, 2, 4, 7, 10, 11, 12, 24, 52, 74, 85, 87, 94, 101, 115, entre otras.

${ }^{76}$ Presentada en sentido negativo, en Cancionero, ed. cit. I, 9: "E creo que fará mal-sen / quen nunca gran fiuz'ouver' / en mesura d'outra molher".

77 Cancionero, ed. cit. I, 304: "Pero quero m'esforçar / con sen e con lealdade / d'amar e seer leal"; I, 307: "Porque sol dizer a gente / do que ama lealmente"; I, 313: "E ben me pode chamar desleal / de querer eu, nen por ben nen por mal / viver com'ora sen ela vivi"; I, 352: "A quen Deus quisesse o poder dar / de lhi fogir, muit'estaria ben, / ca de mil coitas, en que omen ten, / se guardaria, d'aquel desleal / ond'omen non poder aver ergo mal".

${ }^{78}$ Cancionero, ed. cit. I, 275. "Todos dizen que filh'outra senhor, / e que me punhe ben de me quitar / de vos amar, pois non ei voss'amor"; I, 276: "Enquant' eu vivo for', / non quer' outra senhor filhar / se non vos, se vos non pesar"; I, 309: "Mais lo poder ja non é meu: / ca o dem' agora d'amor / me fez filhar outra senhor".

79 Reclamada y predicada de ambas partes, en Cancionero, ed. cit. I, 9, 31, 117, 230, 250, 254, 307, 313, 325, 365, 383, 387, 434, 445. Para Carolina Michaelis de Vasconcelos, en "Glossario do Cancioneiro da Ajuda", en Revista Lusitana, XXIII, 1-4 (1920), p. 55, la voz "Mesura" se identifica con comedimiento, moderación, justa medida, cortesía o maneras palaciegas, cualidades reclamadas y reclamables de ambas partes intervinientes.

${ }^{80}$ Cancionero, ed. cit. I, 6: "Mais vos en preito sodes en"; I, 10: "Per meu preito mal embarazado"; I, 63: "En me de seu preito e de si quitar"; I, 210: "Pois me levo, sol non é en preito"; I, 291: "Preito me trage de me fazer ben"; I, 367: "Mais Deus, que preito tan desaguisado / de poderdes vos teer negado / tan muito ben como vus quis Deus dar".

${ }^{81}$ Premio en el sentido de valor, mérito, gloria, buenas cualidades, en Cancionero, ed. cit. I, 11, $85,86,232,255,257,269$.

${ }^{82}$ Es la lógica que se impone: el buen vasallo recibe del buen señor buen galardón, en Cancionero, ed. cit. I, 303: "Ca pois omen ben serv' a bon senhor, / bon galardon deve d'ess' a levar"; I, 307: "Porque sol dizer a gente / do que ama lealmente: / se s'én non quer enfadar, / na cima gualardon prende".

${ }^{83}$ Cancionero, ed. cit. I, 254: "Por mercê é que vus venho pedir / e porque soo vosso, e porque non / cato por al, nen seria razon". 
pensa a ese cúmulo de servicios. Se presentan a sí mismos como el modelo perfecto de vasallo lo que requiere ahora idéntico modelo de señor. Y ese modelo de señor solamente se puede materializar mediante la entrega del amor que el vasallo pide. Si no es así, no habrá cumplimiento. Todos ellos ponen de relieve un dato evidente: su amor se configura como servicio, de suerte tal que amar y servir son sinónimos, intercambiables, idéntica idea para la mentalidad del momento: el Amor es el servicio por excelencia al que tienden las dos partes del pacto vasallático estipulado ${ }^{84}$.

La relación entre la señora y el poeta vasallo se articula siguiendo los cauces de la normalidad feudal. El amor es el servicio principal, pero no el único. El amor del poeta contiene la esencia de aquello que éste está dispuesto a brindar a su amada. El servicio se resume en el amor, un amor unidireccional, porque no implica de modo necesario la reciprocidad, como ya se ha visto ${ }^{85}$. Pero el amar adopta diferentes formas, pautas, códigos y conductas. Servir es amar, es desear siempre el bien, es cantar a la mujer amada, pero es también el elenco de las prestaciones típicamente feudales: aconsejar y ser aconsejado por la señora ${ }^{86}$; ayudar y ser ayuda-

${ }^{84}$ Ejemplos múltiples en Cancionero, ed. cit. I, 3: "Ben-no creede, mais por vus buscar / muito serviç'enquant'eu vivo for"; I, 37: "E sempre serviç'e amor"; I, 65: "Pola veer moiro e pola servir"; I, 71: "Que meu serviço non me quer"; I, 83: "Pois contra vos non me val, mia senhor, / de vus servir, nen de vus querer ben"; I, 95: "Que seu serviço non lhe quer / per nulha guisa gradecer"; I, 121: "Senhor fremosa, que sempre servi"; I, 137: "Nunca fiz cousa de que me tan ben / achasse come de quanto servi / sempr'una dona , des quando a vi"; I, 204: "Nen quitarei, enquant'eu vivo for', / de vus servir, senhor, e vus amar"; I, 232: "Trobei eu tanto, e tanto a servi"; I, 253: "Nen quer que eu seja seu servidor"; I, 254: "E porque soo vosso servidor"; I, 260: "Que m'el dá por mia senhor, que servir"; I, 268: "Pois se non dol Deus de mi, nen Amor, / nen vos, senhor, que eu sempre servi"; I, 272: "Senhor fremosa, queria saber / de vos que sempre punhei de servir"; I, 291: "A mia senhor, que eu mais d'outra ren / desejei sempr'e amei e servi"; I, 307: "Non pesasse meu serviço"; I, 334: "Pois me non val / contra vos serviço, nen al / que vus faça"; I, 418: "De min podedes vos, senhor, seer servida"; I, 467: "A que eu muito servi".

${ }^{85}$ Cancionero, ed. cit. I, 291: “A mia senhor, que eu mais d'outra ren / desejei sempr'e amei e servi".

${ }^{86}$ Una suerte de consejo universal es el que se busca, pues se pide a los cercanos, y amigos, a la señora, todo ello para acabar con las dolorosas cuitas de amor, si bien la señora muchas veces no responde, sumiendo al poeta en una mayor tristeza (otro incumplimiento más de sus deberes), en Cancionero, ed. cit. I, 10: "Que sen conselho que vos, mia senhor, / me en este mundo fazedes viver"; I, 24: "Senhor fremosa, fui buscar / conselh', e non-no pud'aver"; I, 30: "E pois que lh'esto feit'ouver, / outro conselho á i d'aver"; I, 51: "Mal conselhado que fui, mia senhor"; I, 52: "Que non acho que / me dê conselho, nen vos non mi-o dades"; I, 53: "Quen me conselho der', terrei / que muit' é bon conselhador"; I, 68: "En gran coita vivo, senhor, / a que me Deus nunca quis dar / conselho"; I, 134: "E por en non / me sei conselho, nen sei ora ben / se prove d'ir, se non; e meu sen / e meus conselhos todos aqui son"; I, 154: "Ay eu cativo, que non poderei / prender conselho, pois sen vos ficar"; I, 253: "Mais eu que me faço conselhador / d'outros, devera pera min prender / tal conselho"; I, 275: "Este conselho non poss'eu filhar". 
do; proteger y ser protegido; amparar y ser amparado ${ }^{87}$; obtener su perdón, caso de haberle sido desleal ${ }^{88}$; es estar sometido a peleas ${ }^{89}$, a menguas de la propia hacien$\mathrm{da}^{90}$, a los celos ${ }^{91}$, en aras de la misma felicidad de la señora a la que se sirve incondicionalmente.

Reciprocidad a ultranza, por cuanto que el bien de señora es el fin principal de la relación, un bien por el que se sacrifica todo, un bien perpetuo y por encima de cualquier $\operatorname{cosa}^{92}$, pero sin descuidar el hacer o procurar el bien del vasallo, que también se persigue ${ }^{93}$, que es asimismo un derecho y por eso se le permite la queja ${ }^{94}$. Si ella no cumple, que será lo usual, el poeta queda desemparado, cautivo, solo, indefenso, desprotegido ${ }^{95}$. Es éste su habitual estado de ánimo, con la cuita de amor persiguiéndole en todo lugar y en todo momento. Un estado que procede de la con-

${ }^{88}$ Cancionero, ed. cit. I, 29: "Pero lhe nunca mal busquei, / ei lh'ora de buscar perdon, / ca me quer mal de coraçon".

${ }^{89}$ Peleas incluso contra Dios, a quien se acusa de causar ese mal de amores, en Cancionero, ed. cit. I, 146: 'E des osmais non pod' el saber ren / de mia fazenda, se non devinhar', / pois el assi quer migo guerrejar".

${ }^{90}$ Cancionero, ed. cit. I, 160: “A coita que eu prendo, non sei quen atal prenda, / que me faz fazer sempre dano de mia fazenda".

91 Cancionero, ed. cit. I, 165: “E tenho que faço dereit' e sen / en querer mal quen vus quer mal e ben".

92 Cancionero, ed. cit. I, 3. "Deu-lo sabe, ca nunca desejei / ben d'este mundo se o vosso non"; I, 14: "Nen o pesar / que vus eu faço en vus querer / ben"; I, 16: "Muitas vezes en meu cuidad / ei eu gran ben de mia senhor"; I, 26: "Muito per dev'a gradecer, / (segund'agora meu cuidar) / a Deus, a quen faz ben querer / senhor"; I, 33: "Como desejar ben-fazer / da mui fremosa mia senhor"; I, 36: "Ca vus ei mui gran ben-querer"; I, 116: "E min, senhor, porque vus quero ben”; I, 196: "Com'eu vejo da que quero gran ben"; I, 222: "E vus dixe ca vus queria ben"; I, 226: "Dereito faç en vus querer gran ben"; I, 260: “Que servir / ei, mentr'eu viver"; I, 288: "Nen desejei al nada / se non vosso ben, pois vos vi"; I, 298: "Por una dona que quero gran ben".

93 Cancionero, ed. cit. I, 6: "Se me vos non fazedes ben”; I, 49: “O que conselh'a min de m'eu quitar / de mia senhor, porque me non faz ben"; I, 50: "Ca se me vos, senhor, fezerdes ben"; I, 52: "E ja mais nunca m'outro ben façades"; I, 75. "E se m’él á de fazer algun ben”; I, 125: “Ca non á Deus sobre vos tal poder / per que me faça vosso ben aver"; I, 177: "Ben querria que me fezesse ben"; I, 205: “Ca ela ja non m’á ben de fazer”; I, 209: "Sempr'eu, senhor, roguei a Deus por mi / que me desse de vos ben"; I, 333: "Sabor avedes de me non fazer / ben, mia senhor"; I, 336: "Pero non me fazedes vos por en / mayor ben ca se vus eu o peyor".

94 Cancionero, ed. cit. I, 90: "E gran dereito por faç'i; / e mais me devia queixar"; I, 112: "Non me queredes, mia senhor, / fazer ben"; I, 113: "Rogaria eu mia senhor / por Deus que me fezesse ben"; I, 268: "Mui gran dereito faç'en me queixar / de vos, senhor, eno meu coraçon"; I, 271: "E nunca fezestes por mi / ren"; I, 272: "Senhor fremosa, queria saber / de vos que sempre punhei de servir".

95 Cancionero, ed. cit. I, 32: “E ¿Qué farei eu, catov' e cuitado? / Que eu assi fiquei desamparado / de vos, por que cuita grand' e coidado"; I, 43: "E mal pecado; Moir'og' eu assi, / de mia senhor longe e desamparado"; I, 59: "Por Deus, senhor, non me desamparedes"; I, 199: "E pois me queria desamparar, / quando a vi, mandasse me partir / logo de si"; I, 206: "E mia senhor non me quer valer i, / e assi fiquei desamparado"; I, 289: "Mais rog'a Deus que desampar / a quen m'assi desamparou". 
culcación de las cláusulas no escritas de la relación vasallática establecida, que provoca la frustración jurídica y con ella la anímica.

Servir, en sus líneas generales, implica desear siempre el bien de su señor ${ }^{96}$ y someterse a sus designios en todo caso y lugar ${ }^{97}$. Es el "fazer ben" que se reclama de ambas partes ${ }^{98}$. El poder es exclusivamente de la señora, la que es llamada señora poderosa ${ }^{99}$, y al vasallo solamente le queda plegarse al mismo, aceptarlo todo tal y como viene, sin posibilidad de liberación ${ }^{100}$. Servirla y para ella trabajar, sumergirse en los caprichos y deseos de la misma, de una manera absoluta, ilimitada ${ }^{101}$, con la responsabilidad de Dios subyaciendo en el discurso amoroso ${ }^{102}$, al que se pide auxilio ${ }^{103}$. Ella es, dice Nuño Eanes Cerceo, la muerte, todo mal y todo bien ${ }^{104}$, la totalidad para lo bueno y para lo malo. Servir es, en última instancia, esa sujeción plena que lleva a cumplir todos los mandatos derivados de la sola voluntad de la señora. Es la aniquilación de una voluntad propia que ha sido enajenada a favor del ser amado ${ }^{105}$.

${ }^{96}$ Como hace Pero da Ponte, en Cancionero, ed. cit. I, 288: "E o dia que vos eu vi, / senhor, en tal ora vus vi / que nunca dormi nada, / nen desejei al nada / se non vosso ben, pois vos vi!".

97 Cancionero, ed. cit. I, 68: "Senhor, que assi morrerei, / pois assi é vosso prazer".

${ }^{98} \mathrm{El}$ "fazer ben" y su consecuencia, el beneficio, son sinónimos del verbo amar, tanto para el vasallo como para el señor. El vasallo ha servido bien a la señora amándola; lo que espera ahora es la misma conducta para con él, el bien hacer es aspiración a ser amado. Vid. Spina, S., "O fazer ben dos cantares trovadorescos", en Revista Brasileira de Filologia, II, 2 (1956), pp. 179-186.

${ }^{99}$ Cancionero, ed. cit. I, 361: "Senhor fremosa, / de mi poderosa".

100 Cancionero, ed. cit. I, 7: "Vos que mi-assi cuitades, mia senhor, / que eu me quite de vus ben querer, / de pran ¿cuidades que algun poder / ei eu, senhor, de me vus en quitar? / ca vos por al non o ides fazer. / Mais a verdade vus quer'eu dizer: / este poder nunca mi-o Deu quis dar".

${ }^{101}$ El señor aprisiona al vasallo, en Cancionero, ed. cit. I, 41: "E essa me ten en poder, / e essa est a mia senhor, / e essa me faz o mayor / ben d'este mundo desejar"; I, 250: "En que me ben mostrass' o seu poder"; I, 285: "Sen vos, que me teedes en poder"; I, 296: "Una dona que me ten en poder"; I, 305: "Una dona que quero mui gran bem; / e muit' á ja que m'en seu poder ten"; I, 306: "Ca senhor ei que me ten en poder"; I, 440: "Nen saben qual coita mi faz sofrer / esta senhor que me ten en poder".

102 Cancionero, ed. cit. I, 40: "Ay mia Senhor, se eu non merecesse / a Deus quan muito mal lh'eu mereci, / d'outra guisa pensara el de mi / ca non que m'en vosso poder metesse. / Mais soube-lh'eu muito mal merecer / e meteu-m'el en o vosso poder / u eu jamias nunca coita perdesse"; I, 427: "E mia senhor, mui gran poder vus deu / Deus sobre min".

${ }^{103}$ Cancionero, ed. cit. I, 54: "E Deus, se vus for' en prazer, / sacade-me de seu poder".

104 Cancionero, ed. cit. I, 386: "Vos sodes mia morte, e meu mal, e meu ben".

105 Mandado como aviso, anuncio, recado de la señora, pero siempre con ese componente de ordenación, de coactividad, que deriva de la relación feudal, en Cancionero, ed. cit. I, 8: "Ca ja eu sempre guardar-m'ei / d'aver mais ben do que og'ei, / se por vosso mandado non"; I, 304: "Ca sempr'eu serei pagado / de quanto s'ela pagar', / e de fazer seu mandado, / se m'ela quiser' mandar"; I, 332: "Digas-me mandado de mia senhor"; I, 343: "E mui longi d'oir vosso mandado"; I, 347: "Poi-la que non fosse nada / por mi é tan alongada / de min, que non sei mandado / d'ela, nen de mia fazenda"; I, 355: "Nenhun conselho boo que filhar, / porque non fiz seu mandado enton"; I, 414. "Pois minha senhor me manda". 
Como forma última de mostrar ese amor, ese servicio, y de plasmar en la realidad cotidiana el mismo, hallaríamos el propio arte de trovar, es decir, la escritura y la canción como arma al servicio del mismo amor feudal, dado que esa exaltación es también una forma de servicio en su máxima expresión ${ }^{106}$. La pena viene causada precisamente por aquellos casos en los cuales la señora no acepta los servicios del vasa1lo. Cobra tintes de inmensa amargura y de dolor prácticamente infinito. La muerte del vasallo parece ser la conclusión necesaria, de la cual no está excluida la voluntad del señor, es decir, que éste pudo bien decidir de modo voluntario ese estado previo e inevitable a la muerte al que se ve irremisiblemente destinado el servidor.

Pero la relación feudo-amorosa implica más detalles. Otro de los elementos que tipifican aquélla y que es reiterado por el poeta consiste en el silencio respecto a la denominación de la mujer amada. Ninguna de las composiciones, salvo contadas excepciones, se refiere nunca a la amada empleando su propio nombre. Acaso es otro de los deberes que se imponen al vasallo y que éste debe cumplir escrupulosamente. El silencio, como medida de precaución para evitar que se descubra esta infidelidad en ciernes, que sea comentada por los demás competidores y descubierta por el marido, caso de existir aquél. Fernán González de Seara es el trovador que hace una aproximación más certera a este deber previo, cuyo incumplimiento podría provocar la demolición del edificio en construcción, de esa relación que se está fraguando entre las partes. El poeta se niega a revelar el nombre de la señora amada mientras esté vivo porque de ello no se derivaría ningún beneficio para ambos, sino todo lo contrario. Aunque se lo pregunten de buena fe, él responde con el silencio o con alguna mentira piadosa en este caso ${ }^{107}$. En otro ejemplo, el mismo

106 Cancionero, ed. cit. I, 232: “A boa dona, por que eu trobava”; I, 247: “Que mui grad' eu querria fazer / una tal cantiga por mia senhor / qual a devia fazer trobador / que atal senhor fosse ben querer (...) Tan muit'avia mester de saber / trobar mui ben quen por atal senhor / trobar quisesse"; I, 279: "Pero eu vejo aquí trobadores , / senhor e lume d'este olhos meus, / que troban d'amor por sas senhores / non vej'eu aquí trobador, par Deus"; I, 306: "E porque m'ora quitei de trobar, / muitos me teen por quite d'amor"; I, 346: "Pero que mia senhor non quer / que por ela trobe per ren, / nen que lhi diga quan gran ben / lhi quero, vel en meu cantar"; I, 352: “Ja m'eu quisera leixa de trobar, / se me leixass' a que mi-o faz fazer"; I, 372: "Muitos teen oje por meu trobar / ca mi-o non faz nulha dona fazer; / e be-no poder pora si teer"; I, 446: "Muitos me preguntan, per boa fe, / preguntas que non devian fazer, / que lhes diga por quen trob', ou qual é".

107 Cancionero, ed. cit. I, 446: "Muitos me preguntan, per boa fé, / preguntas que non devian fazer, / que lhes diga por que trob', ou qual é. / E por en ei a todos a dizer / ca non saberan quen é mia senhor, / per mi, entanto com'eu vivo for'. / En lh'o dizer non seria mia prol; / et eles, pois, mi-o terrian per mal, / se lh'o dissesse; e des i per fol / me terriam; e digo-lhes eu al: / ca non saberan quen é mia senhor, / per mi, entanto com'eu vivo for'. / ¿E que an consigo de mi aficar / que lhes diga, qual é a senhor que ei? / E en al deverian a falar, / que seria mais sap rol; e direi / ca non saberan quen é mia senhor, / per mí, entando com'eu vivo for'. 
González de Seara reitera esa negativa a revelar el nombre de la amada ante la pléyade de personas que le preguntan "qual est a dona que eu quero ben", pero él no lo dirá bajo ningún concepto, ni bajo ningún ofrecimiento ("Mais mia senhor non saberan por ren"):

"E mui ben vej'eu que perden seu sen

Aqueles que me van a demandar

Quen é mia senhor; mais eu a negar

A averei sempre jassi me venha ben!

Eu ben falar ei da sa fremosura,

E de sabor; mais non ajan en cura,

$\mathrm{Ca}$ ja per min non saberan mais en"108.

Es éste el primero de los deberes del poeta porque la ocultación de aquellos protagonistas (en este caso, de la protagonista) determinará el éxito o el fracaso final del proyecto conjunto que está creando. Su empleo es común, frecuente, reiterado ${ }^{109}$. De la discreción depende que se materialice o no ese amor. Esto no es obstáculo para que en algunos casos muy puntuales se den indicaciones de parentes$\mathrm{co}^{110}$ o nominales ${ }^{111}$, pequeñas pistas, que bien pudieran ser falsos para evitar cualquier suerte de peligros. Pero lo usual es el silencio: aunque el dolor sea inmenso, no se pronuncia nunca el nombre de la señora ${ }^{112}$.

Servir y callar. Las más de las veces, sufrir. Mas no hay una total indefensión, dado que ese vasallo trovador tiene algún recurso para actuar en su propio provecho y erradicar ese sufrimiento generalizado. Partir de la señora, abandonarla,

108 Cancionero, ed. cit. I, 447.

109 Cancionero, ed. cit. I, 30, 48, 184, 220, 228, 245, 246, 405, 446, 447.

$110 \mathrm{O}$ bien se refiere a su madre, como en Cancionero, ed. cit. I, 238: "Mais pois que ja non posso guarecer, / a por que moiro vus quero dizer: / diz alguen: est'é filha de Maria". O bien se indica un grado de parentesco con el poeta o con otra persona, en Cancionero, ed. cit. I, 38: "E vos, fiha de don Paay / Moniz"; I, 426: ante la pregunta de quién le hizo perder el sentido, el poeta Fernán Fernández Cogomiho responde: "A mia sobrinha mi tolheu / o sen, por que ando sandeu"; I, 398: "Netas de Conde, viuvas nen donzelas": I, 426: "A mia sobrinha mi tolheu / o sen, por que ando sandeu". Incluso una mujer perteneciente a la clerecía como la monja que no es de Nogueira, en Cancionero, ed. cit. I, 282: "Non est a de Nogueira / a freira que m'en poder ten".

${ }^{111}$ Cancionero, ed. cit. I, 62: "Pois non ei de dona "lvira / seu amor e ei sa ira"; I, 89: "Joana est ... ou Sancha ... ou Maria”; I, 104: "Joana, dix’eu, Sancha e Maria”; I, 105: "Joan'ou Sancha, que dix’, ou Maria”; I, 106: “Se é Joana? Se Sancha? Se quen? / Se Maria?”; I, 142: “A morte d'esto se mata: / Guiomar Affonso Gata / est a dona que me mata"; I, 143: "Eu soo Guiomar Affonso!"; I, 198: "Par Deus, ay dona Leonor, / gran ben vus fez Nostro Senhor!"; I, 301: "Se eu ousass' a Mayor Gil dizer"; I, 375: "Viv' en mui gran tormenta / dona Orrac' Abril"; I 392: "Par Deus, dona Maria, mia senhor ben-talhada"; I, 455: "Foi Oordia Gil e foi Guiomar".

${ }^{112}$ El poeta jamás dirá el nombre de la señora, como en Cancionero, ed. cit. I, 28; I, 48; y I, 245. 
es el recurso superior y último al que accede el vasallo, porque, como ya se ha visto, soportando como soporta la total infelicidad, queda siempre el rescoldo de una aspiración, un deseo o una pequeña esperanza de que la señora cambie de actitud. El vasallo podía, siguiendo el mismo procedimiento que se había establecido para el homenaje, separarse de su señor por su sola voluntad desde el siglo XII, sin necesidad de que concurriese causa justificada alguna ${ }^{113}$. Las Partidas hablan de "partir" o "despedir" el vasallo"114. Es el recurso último al que acuden algunos trovadores: solamente cabe la posibilidad de prolongar la angustia hasta la muerte o bien conservar la vida, lo que exige un alto sacrificio cual es el abandono, la renuncia, el intento de olvidar a su señora. La solución, el partir (antónimo de "ficar", permanecer, o de "quitar", liberarse), el desnaturalizarse, es solución contemplada y practicada por algunos poetas como única vía de aliviar el sufrimiento ${ }^{115}$. Claramente, ese dolor mezcla de alivio y de nostalgia, lo expone Nuño Eanes Cerceo, que renuncia a su tierra y a sus amigos para olvidar a su señora:

“Agora me quer' eu ja espedir

Da terra, e das gentes que i son,

U mi Deus tanto de pesar mostrou,

E esforçar mui ben meu coraçon,

E ar pensar de m'ir alhur guarir.

E a Deus gradesco porque m'en vou.

Ca meu grad', u m'eu d'aquí partir,

Con seus desejos non me veeran

Chorar, nen ir triste, por ben que eu

Nunca presesse; nen me poderan

Dizer que eu torto faç' en fogir

D'aquí u me Deus tanto pesar deu"116.

En algunos de ellos, aun con todo el dolor, la solución no aparece nítidamente y las reservas son numerosas porque están acaso convencidos de que esa separación no

113 Vid. García de Valdeavellano, L., Curso de Historia de las instituciones españolas. De los orígenes al final de la Edad Media. 2a edición corregida y aumentada, Madrid, 1970, pp. 384-385.

114 Partida 4, 25, 7.

115 Cancionero, ed. cit. I, 18: “Agora m'ei eu a partir / de mia senhor, e d'aver ben / me partirei poi-la non vir"; I, 21: "E pero no direi por quen; / mais per muitas terras irei / servir outra, se poderei / negar esta que quero ben"; I, 126: "Punhei eu muit'en me quitar / de vos, fremosa mia senhor"; I, 424: "E quando m'eu da mia senhor parti".

116 Cancionero, ed. cit. I, 389. 
pondrá fin al dolor, sino que originará otro más fuerte ${ }^{117}$. Incluso es imposible como afirma el poeta: "de non poder d'ela partir / os meus olhos"118, debido al miedo que ha inculcado en el alma de aquél ${ }^{119}$. En ocasiones, el dolor lo causa la marcha de la propia señora ${ }^{120} \mathrm{o}$ es ésta la que fuerza al poeta al abandono del amor, lo cual implicaría un abandono también físico ${ }^{121}$. Un trovador desconocido nos cuenta que desde la separación no ha habido tranquilidad, ni reposo, ni alegría en su vida:

\author{
"Amigos, des que me parti \\ De mia senhor e a non vi, \\ Nunca fui ledo, nen dormi, \\ Nen me paguei de nulha ren"122.
}

Una consecuencia que se sugiere en algunos textos es la posible venganza que la señora ejercita sobre el vasallo. Aparece en Nuño Rodríguez de Candarey, quien afirma que vive en gran dolor pues Dios no le ha dado consejo alguno y aboga por la muerte como única salida lógica a su sufrimiento. Esa solución puede actuar como motor de la venganza, traducida en el mal hacer de la señora, que sobre el vasallo se proyecta en caso de que ejecute su amenaza, la cual provocará un menoscabo en las expectativas de la señora claramente:

117 Cancionero, ed. cit. I, 15: “Ca sempre eu desejei mais d'al / de viver con ela e, mal / que me pes, a partir-m'ei en"; I, 23: "E se m'ela por Deus mandasse / o que me nunca quis mandar / que me non fosse, e que ficasse / ali u ela ouvess'estar"; I, 103: "De que m'eu trist' e chorado parti / e muit' anvidos e mui sen sabor, / porque me disse que me partiss'en / a mia senhor e meu lum' e meu ben, / mais fremosa das donas que eu vi"; I, 135: "Nostro Senhor, ¿e ora que será / de min, que moiro, porque me parti / de mia senhor mui fremosa"; I, 174: "Noutro dia, quando m'eu espedi / de mia senhor, e quando mi-ouv'a ir"; I, 290: “Agora me part'eu mui sen meu grado / de quanto ben oge no mund'avia"; I, 294: "Veed', amigos, como m'en parti: / Leixei-lh'a terra, por lhe non fazer / pesar, e viv'u non posso viver"; I, 357: “Grave dia naceu, senhor, / quen se de vos ouv'a partir, / e se teve por devedor / de se a outra terra ir / como m'eu de vos partirei. / Ora quando m'alongarei / de vos, viverei sen sabor"; I, 360: "Vedes, senhor, u m'eu parti / de vos, e vus despois non vi, / ali tenh'eu o coraçon"; I, 391. “Con gran coita de vos direi-vo'-lo que farei: / leixar quer' a terra u vos sodes, senhor (...) E se me Deus quisess'oir, alá morrerei”; I, 397: “Cuidava-m'eu, quando non entendia / que mal-sen era de vus ben querer, / senhor fremosa, que m'en partiria (...) pero non me part'en".

118 Cancionero, ed. cit. I, 28.

${ }^{119}$ Cancionero, ed. cit. I, 61: “Ca eu, ¿como vus fogirei, / pois estes, de que tal med'ei, / me non leixan de vos partir? / E pois m'alhur non leixan ir, / estar-lhis-ei mentr'eu poder”.

120 Cancionero, ed. cit. I, 70: "Ir-vus queredes, mia senhor, / e fiqu'end'eu con gran pesar (...) E rogu'eu a Nostro Señor / que, se vos vus fordes d'aquen, / que me dê mia morte por en, / ca muito me será mester"; I, 199: "E pois me queria desemparar, / quando a vi, mandasse me partir / logo de si; e mandasse-m'end ir"

121 Cancionero, ed. cit. I, 73: “Ora veg'eu que me non fará ben / a mia senhor, pois me mandou dizer / que me partisse de a ben querer".

122 Cancionero, ed. cit. I, 280. 
"E por meu mal se me deten, Por vingar-vus, mia senhor, ben De min, se vus faço pesar"123.

La venganza pertenece en otros casos a Dios, que la proyecta sobre el infeliz poeta vasallo, quien ignora los motivos últimos de la aquélla, el por qué íntimo de esa actuación contra él. Es ahora Pedro García Burgalés:

"Se eu a Deus algun mal mereci,

Gran vingança soub' el de min prender,

Ca me fez mui boa dona veer

E mui fremos', e ar fez-me des i

Que lhe quis sempre d'outra ren melhor"124.

Y en idéntico sentido canta Joan de Aboin sus cuitas de amor:

"Be'-no sei eu, fez mi-o por se vengar

De mi, per esto e non per outra ren;

Se lh'algun tempo fiz pesar por en

Me leix'assi desempard'andar

E non me quer contra ela valer.

Por me fazer mayor coita soffrer

Me faz tod' est', e non me quer matar" 125 .

Otras veces, es el propio poeta quien ejercita la venganza contra sus propios ojos, instrumentos que le servían para percibir a la señora amada y con ello incrementar sus dolores espirituales para hacer "seu mal e do meu coraçon / por me vengar d'eles, e por al non", aunque el resultado final es que:

"Na vengança que d'eles prendi,

Gran mal per fiz a eles e a mi" 126 .

Pocas son, por el contrario, las duras palabras de traición que figuran en el texto, en cuanto que extremo máximo de la infidelidad. Parece ser éste el recurso último que solamente se emplea en contadas ocasiones para designar el comportamiento del señor o del vasallo. Como sucedía en la realidad cotidiana, la traición

${ }^{123}$ Cancionero, ed. cit. I, 68.

124 Cancionero, ed. cit. I, 100.

125 Cancionero, ed. cit. I, 157.

126 Cancionero, ed. cit. I, 164. 
es suceso excepcional, dentro del edificio de fidelidades que sostenían el aparato político y pocas veces se realizaba una conducta tal. La gravedad de las penas previstas en la antgua legislación visigoda, así como en el conjunto de textos romanos, provocaría en muchas ocasiones un retraimiento en el desarrollo de conductas tales. El respeto a la palabra dada y el haz de consecuencias jurídicas que el incumplimiento imponía hacían difícil ese paso hacia dichos comportamientos, que rebasaban los márgenes de las lealtades conocidas ${ }^{127}$. Lo mismo en el campo amoroso. Es el comportamiento más deleznable porque supone la violación de toda idea de lealtad existente, y de lo que ella comporta, esencialmente, la seguridad en cuanto que orden y paz. Y ese comportamiento es el que fundamentalmente en la época del cancionero se debía al monarca, no a ningún otro ser. De modo que se asiste así a una cierta vulgarización de la idea de traición, puesto que los sujetos que traicionan o a los que se puede traicionar son innúmeros. Veamos ejemplos de esa pluralidad subjetiva. Lo expone Joan Coelho en un sentido trágico e irresoluble, dado que si muere por ella o ella muere a manos del vasallo, la solución es la misma, en el sentido de ser calificado de violador de esa fidelidad, por tanto, de traidor:

\footnotetext{
"Quen me vus assi vir'desamparar

E morrer por vos, pois eu morto for',

Tan ben vus dirá por mi traedor

Come a min por vos, se vus matar" 128 .
}

La traición es vista, sobre todo, como un incumplimiento de los deberes fundamentales, tanto jurídicos como emocionales. Es traición la no protección del bien que se tiene puesto que hace gran daño el que tiene un bien, siempre que su corazón no lo guarde o proteja en toda ocasión:

"E faz gran traicion

O que ben á, se o seu coraçon

En al pon nunca se non en guardar

Sempr' aquel ben" 129 .

\footnotetext{
127 Vid. Iglesia Ferreirós, A., Historia de la traición. La traición regia en León y CaStilla, Santiago de Compostela, 1971, especialmente, pp. 147 ss., para la obra alfonsina, donde acaba cuajando una idea de traición como violación de la lealtad debida al monarca (sobre todo, en Espéculo y Partidas), es decir, al señor natural por antonomasia.

128 Cancionero, ed. cit. I, 158.

129 Cancionero, ed. cit. I, 248.
} 
Pero también es traición no agradecer el sacrificio del vasallo, entendiendo por tal la ausencia de recompensa o de galardón por sus servicios, incluso la muerte a favor o en beneficio del señor:

"Mais por Deus, que vus foi dar o mayor

Ben que eu d'outra dona oí dizer,

Que me non leixedes escaecer

En me lhe non deffenderdes, senhor!

Ca ben coido, de com'é traedor,

Que me mate ced', e pois non querer

Gracir-vo'-lo, pois que eu morto for" ${ }^{\text {"130. }}$.

En otros supuestos, el calificativo de traidor se aplica al propio Amor, al mismo sentimiento que con tan mala fortuna ha irrumpido en la vida de los protagonistas:

"Mais esso pouco que eu vivo for',

Pois assi é,no'-me queiro queixar

D'eles; mais el seja seu traedor,

Se me non mata, ois non poss'achar

Quen me lh'ampar, e se me d'el queixar,

Deus non-me valha! Que eu mester ei”"131.

Ningún hombre ha sido leal al Amor, en sentido inverso, y muchos se quejan junto al trovador de las injusticias que aquél comete y de cómo la posibilidad de huida sería bien empleada en la mayor parte de los casos:

"A quen Deus quisesse o poder dar

De lhi fogir, muit'estaria ben,

Ca de mil coitas, en que omen ten,

Se guardaria, d'aquel desleal

Ond'omen non poder aver ergo mal.

Ed Amor nunc'a ome leal vi,

E vejo eu muitos queixar con mi"132.

La señora no se escapa a la calificación de traidora. Fernán Paes de Talamancos denuncia a su amada sin miedo a las represalias. Anuncia su despedida precisamente por que ella le ha traicionado, le ha querido mal:

${ }^{130}$ Cancionero, ed. cit. I, 263.

${ }^{131}$ Cancionero, ed. cit. I, 264.

${ }^{132}$ Cancionero, ed. cit. I, 352. 


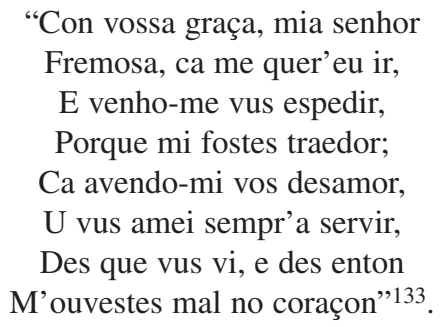

En algunas cantigas, el traidor es el corazón que no se aviene a razones concretas para justificar los desvaríos cometidos, un corazón que da malos consejos e incrementa le dolor:

"E des que a vi o primeiro dia,

Non me guardei, nen fui en sabedor, Nen me quis Deus guardar, nen mia folia,

Nen este meu coraçon traedor Que mi-a depois conselhou a veer"134.

Finalmente, el calificativo de traidor se emplea para referirse al propio mundo, el estado de las cosas, que ha impedido que aquéllas discurrieran por los cauces de la normalidad y que el Amor se consumase:

'E por esto quer'eu por seu amor

Leixa'-lo mundo falso, traedor,

Desemparado, que me foi falir" ${ }^{135}$.

Con estas líneas he tratado de mostrar la comunicación e interdependencia, la relación nítida y el intercambio fluido, entre lenguajes, el jurídico, vasallático o feudal, y el amoroso, así como la transposición de los esquemas de esa relación señor-vasallo al campo amoroso. Se han examinado vocablos referidos a las partes (señores, vasallos, hombres, servidores), a las modalidades del servicio, al amparo y al desamparo, al cautiverio, a los pactos, homenajes y demás parafernalia usada con regularidad en la concertación de esas relaciones de fidelidad extremas y especiales. Falta, y es ausencia cualificada, la mención al feudo, pero las mismas razones que explican su presencia contada en no más de cinco casos dentro de la prosa cortesana o cancilleresca, en la documentación oficial, pueden servir de explicación

133 Cancionero, ed. cit. I, 358.
134 Cancionero, ed. cit. I, 406.
135 Cancionero, ed. cit. I, 438. 
y de justificación de la misma ausencia en el campo de la lírica, tan próximo a los sentimientos y realidades que aquél pretendía regularizar. Quedan muchas etapas todavía que recorrer en este camino que conduzcan paulatinamente a examinar y desnudar los cancioneros restantes, a leerlos con la vista puesta en una perfecta auscultación de la vida que debajo de su apariencia late, una vida que está llena de múltiples rostros, como el de la poesía o como el del Derecho, con el fin de examinar que esa realidad feudal circundante constituía una atmósfera que lo impregnaba todo, inclusive los sentimientos más íntimos y más alejados, a primera vista, del mundo del Derecho. 